\title{
CK2 Oppositely Modulates L-DOPA-Induced Dyskinesia via Striatal Projection Neurons Expressing D1 or D2 Receptors
}

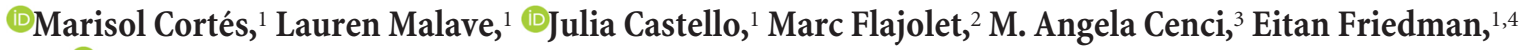 \\ and ${ }^{\circ}$ Heike Rebholz ${ }^{1}$ \\ ${ }^{1}$ Department of Molecular, Cellular, and Biomedical Sciences, CUNY School of Medicine, New York, New York 10031, ${ }^{2}$ Laboratory of Molecular and Cellular \\ Neuroscience, The Rockefeller University, New York, New York 10065, ${ }^{3}$ Basal Ganglia Pathophysiology, Department of Experimental Medical Science, Lund \\ University, 22100 Lund, Sweden, and ${ }^{4} \mathrm{PhD}$ Programs in Biochemistry and Biology, The Graduate Center, City University of New York, New York 10016
}

We have previously shown that casein kinase 2 (CK2) negatively regulates dopamine D1 and adenosine $\mathrm{A}_{2 \mathrm{~A}}$ receptor signaling in the striatum. Ablation of CK2 in D1 receptor-positive striatal neurons caused enhanced locomotion and exploration at baseline, whereas CK2 ablation in D2 receptor-positive neurons caused increased locomotion after treatment with $\mathrm{A}_{2 \mathrm{~A}}$ antagonist, caffeine. Because both, D1 and $\mathrm{A}_{2 \mathrm{~A}}$ receptors, play major roles in the cellular responses to L-DOPA in the striatum, these findings prompted us to examine the impact of CK2 ablation on the effects of L-DOPA treatment in the unilateral 6-OHDA lesioned mouse model of Parkinson's disease. We report here that knock-out of CK2 in striatonigral neurons reduces the severity of L-DOPA-induced dyskinesia (LID), a finding that correlates with lowered pERK but unchanged pPKA substrate levels in D1 medium spiny neurons as well as in cholinergic interneurons. In contrast, lack of CK2 in striatopallidal neurons enhances LID and ERK phosphorylation. Coadministration of caffeine with a low dose of L-DOPA reduces dyskinesia in animals with striatopallidal knock-out to wild-type levels, suggesting a dependence on adenosine receptor activity. We also detect reduced $\mathrm{G}_{\text {off }}$ levels in the striatonigral but not in the striatopallidal knock-out in response to L-DOPA treatment.

Our work shows, in a rodent model of PD, that treatment-induced dyskinesia and striatal ERK activation are bidirectionally modulated by ablating CK2 in D1- or D2-positive projection neurons, in male and female mice. The results reveal that CK2 regulates signaling events critical to LID in each of the two main populations of striatal neurons.

Key words: adenosine; CK2; dopamine; dyskinesia; L-DOPA; signaling

Significance Statement

To date, L-DOPA is the most effective treatment for PD. Over time, however, its efficacy decreases, and side effects including L-DOPA-induced dyskinesia (LID) increase, affecting up to $78 \%$ of patients within 10 years of therapy (Hauser et al., 2007). It is understood that supersensitivity of the striatonigral pathway underlies LID, however, D2 agonists were also shown to induce LID (Bezard et al., 2001; Delfino et al., 2004). Our work implicates a novel player in the expression of LID, the kinase CK2: knock-out of CK2 in striatonigral and striatopallidal neurons has opposing effects on LID. The bidirectional modulation of dyskinesia reveals a central role for CK2 in striatal physiology and indicates that both pathways contribute to LID.

\section{Introduction}

Parkinson's disease (PD) is the second most prevalent neurodegenerative disorder, affecting as many as $1 \%$ of people 65 years or

Received Feb. 16, 2017; revised July 14, 2017; accepted July 19, 2017.

Author contributions: M.C., M.A.C., E.F., and H.R. designed research;M.C., L.M., J.C., and H.R. performed research; H.R. contributed unpublished reagents/analytic tools; M.C., L.M., J.C., M.F., and H.R. analyzed data; M.F., M.A.C., E.F., and H.R. wrote the paper.

This work was supported by the RISE program grant NIGMSR25GM056833 (to M.C. and L.M.), the Rapid Response as well as the Dyskinesia Challenge Awards of the Michael J. Fox Foundation for Parkinson's disease, and the PSC-CUNY45 and 46 awards of the City University of New York (to H.R.). We thank M. Sammon for technical assistance, and Drs. M. Zhou, K. Salas-Ramirez, and A. Kottmann for helpful discussions and equipment.

The authors declare no competing financial interests.

Correspondence should be addressed to Dr. Heike Rebholz, Department of Molecular, Cellular, and Biomedical Sciences, CUNY School of Medicine, 160 Convent Avenue, New York, NY 10031. E-mail: hrebholz@med.cuny.edu. older (Hirtz et al., 2007). It is characterized by motor symptoms such as tremor, rigidity, bradykinesia, and gait disturbances (Graybiel, 2000), which are caused by striatal dopamine depletion, engendered by a loss of dopaminergic neurons within the substantia nigra pars compacta (Dauer and Przedborski, 2003).

More than $95 \%$ of neurons in the striatum are GABAergic projection neurons that are categorized in two classes based on their predominant expression of either D1 or D2 receptors (Gerfen et al., 1990). Neurons projecting directly to the basal ganglia output nuclei ("direct pathway") express the D1 receptor (D1R), 
which is positively coupled to cAMP-dependent signaling via $\mathrm{G} \alpha_{\mathrm{s}} / \mathrm{G} \alpha_{\text {olf }}$. The other class of projection neurons ("indirect pathway") expresses the inhibitory, $\mathrm{G} \alpha_{\mathrm{i}}$-coupled D2 receptor (D2R). In these neurons, cAMP signaling is stimulated by the $G \alpha_{s} / G \alpha_{\text {olf }}$ coupled adenosine $\mathrm{A}_{2 \mathrm{~A}}$ receptor (Rosin et al., 2003). The balance between the two pathways, crucial to movement control, is disrupted in PD. Currently, L-DOPA is the most effective symptomatic treatment for PD. Over time, however, the efficacy of L-DOPA decreases, drug dosage is increased, and debilitating involuntary movements develop in the majority of the patients. L-DOPA-induced dyskinesia (LID) affects up to $78 \%$ of patients within 10 years of therapy and represents a major challenge in the clinical management of this disorder (Hauser et al., 2007). Various pharmacological approaches are being developed to delay the need for L-DOPA or mitigate its complications.

CK2 (formerly casein kinase 2 ), a heterotetrameric kinase consisting of two catalytic subunits $(\alpha)$ and two regulatory $(\beta)$ subunits, is a major player in the regulation of cell proliferation and apoptosis. Despite high brain expression levels and activity (Lou et al., 2008), its importance in the brain is poorly understood. Brain CK2 substrates have been linked to a variety of disorders including PD (Castello et al., 2017). CK2 is present in Lewy bodies and phosphorylates $\alpha$-synuclein and synphilin-1 (Ryu et al., 2008). Phosphorylation of the latter seems to impact on the amount of cytoplasmic inclusions (Lee et al., 2004). Constitutive CK2 knock-out (KO) mice are embryonically lethal: $\mathrm{CK} 2 \alpha \mathrm{KO}$ mice die at embryonic day (E) 10.5 with neural tube and heart defects (Lou et al., 2008), and CK2 $\beta$ KO mice die on day E6.5 (Buchou et al., 2003). We have previously provided evidence that CK2 modulates D1R as well as $\mathrm{A}_{2 \mathrm{~A}} \mathrm{R}$ signaling (Rebholz et al., 2013). We found that $C K 2$ binds to $G \alpha_{s} / G_{\text {olf }}$ and that inhibition or knockdown of CK2 leads to elevated cAMP concentrations in response to D1R or $\mathrm{A}_{2 \mathrm{~A}} \mathrm{R}$ agonists (Rebholz et al., 2013). This effect may be mediated through modulation of receptor endocytosis. We have further found that mice with conditional ablation of $\mathrm{CK} 2 \alpha$ in D1- or D2-positive neurons exhibit behavioral phenotypes corresponding to elevated expression/signaling via the D1 or $A_{2 \mathrm{~A}}$ receptor, respectively (Rebholz et al., 2013; Castello et al., 2017).

Due to the importance of $\mathrm{D} 1$ and $\mathrm{A}_{2 \mathrm{~A}}$ receptors in the cellular responses to L-DOPA, our data lead us to hypothesize that CK2 may also play a role in regulating striatal signaling and behavior in PD. We thus set out to examine behavioral and signaling responses to L-DOPA in conditional CK2 $\alpha \mathrm{KO}$ mice rendered parkinsonian by a 6-OHDA lesion. We report that the lack of CK2 $\alpha$ in direct or indirect pathway striatal neurons has opposite effects on dyskinetic behaviors and on the associated striatal upregulation of ERK signaling.

\section{Materials and Methods \\ Animals}

The generation of the floxed CK2 $\alpha$ line was described previously (Gong et al., 2007; Rebholz et al., 2013), mice were continuously kept on a $\mathrm{C} 57 \mathrm{BL} / 6 \mathrm{~J}$ background. Animals that underwent 6-OHDA lesions were of 25-30 g weight (4-6 months old). The mice were maintained in a $12 \mathrm{~h}$ light/dark cycle, with access to food/water ad libitum. Animal procedures were in accordance with the NIH guidelines and approved by CCNY's IACUC. The Drd1a-Cre ${ }^{+/-} ;$CK2 $\alpha^{\text {loxP/loxP }}$ will be named Drd1a-Cre/CK2 ${ }^{\mathrm{KO}}$ and the Drd2-Cre ${ }^{+/-} ; \mathrm{CK} 2 \alpha^{\text {loxP/loxP }}$ will be named Drd2-Cre/CK2 ${ }^{\mathrm{KO}}$, whereas their corresponding control littermates Drd1a-Cre ${ }^{-1-} ; \mathrm{CK} 2 \alpha^{\text {loxP/loxP }}$ or Drd2-Cre ${ }^{-1-} ; \mathrm{CK} 2 \alpha^{\text {loxP/loxP }}$ will be annotated as WT for both lines. The GENSAT BAC Cre-recombinase driver lines Drd1a-Cre and Drd2-Cre were crossed with the floxed animals (Gerfen et al., 2013). The GENSAT BAC Drdla-GFP line
$\operatorname{Tg}$ (Drdla-eGFPX60Gsat) was also crossed with the Drdla-Cre ${ }^{+/-}$; CK $2 \alpha^{\text {loxP/loxP }}$ line.

\section{Antibodies}

Anti-CK2 $\alpha$ (RRID:AB_297213), anti-Enkephalin and anti-GFP (RRID: AB_300798) antibodies were purchased from Abcam, anti-G $\alpha$ from Calbiochem, anti-tyrosine hydroxylase (RRID:AB_390204) and anticholine acetyltransferase (RRID:AB_2079751) from Millipore. Anti-tubulin antibody was purchased from Sigma-Aldrich (RRID:AB_477593). Anti-phospho-Thr202/Tyr204-Erk1/2 (RRID:AB_331646), c-Fos (RRID:AB_2247211), and phospho-(Ser/Thr) PKA substrate (RRID:AB_331817) were from Cell Signaling Technology. The anti-G $\alpha_{\text {olf }}$ antibody was a gift from Dr. D. Hervé (INSERM UMR-S 839, Paris). Various AlexaFluor antibodies were used at a 1:500 dilution for immunohistochemistry (Invitrogen).

\section{6-OHDA lesions and L-DOPA treatment}

Unilateral 6-OHDA injections into the dorsolateral striatum were performed according to a well established method (Francardo et al., 2011). Mice were anesthetized with a mixture of ketamine $(80 \mathrm{mg} / \mathrm{kg})$ and xylazine $(12 \mathrm{mg} / \mathrm{kg})$; the local anesthetic Bupivacaine (Marcaine) was subcutaneously injected near the surgery site. 6 -OHDA- $\mathrm{HCl}(3.0 \mathrm{mg} / \mathrm{ml}$; Sigma-Aldrich) was dissolved in a solution containing $0.2 \mathrm{~g} / \mathrm{L}$ ascorbic acid left striatum at the following coordinates: anteroposterior (AP), $+1.0 \mathrm{~mm}$; lateral (L), $+2.1 \mathrm{~mm}$; dorsoventral (DV), $-3.4 \mathrm{~mm}$; and AP, $+0.3 \mathrm{~mm}$; L, $+2.3 \mathrm{~mm}$; DV, $-3.4 \mathrm{~mm}$. For medial forebrain bundle (MFB) lesion a single injection of $3 \mu \mathrm{g}$ of 6-OHDA at coordinates: -1.2 $\mathrm{AP},-1.3 \mathrm{ML},-4.75 \mathrm{DV}$ from dura was performed. Each injection was performed with a Hamilton needle (33 gauge) connected to a syringe micropump (WPI) by a polyethylene catheter, at a slow rate of $0.4 \mu \mathrm{l} / \mathrm{min}$ to minimize tissue damage. After the injection, the needle was left in place for an additional $4 \mathrm{~min}$ before being slowly retracted. After surgery, animals were kept warm with a heated mat and observed three times daily. If necessary, animals received injections of $4 \%$ sucrose $(10 \mathrm{ml} / \mathrm{kg}$, s.c.) and saline (10 ml/kg, i.p.) as well as hydrogel pouches to avoid dehydration and high-fat chow to reduce weight loss. Mice were allowed to recover for 3 weeks before behavioral evaluation and drug treatment. Lesions were assessed biochemically at the end of experiments by determining the striatal levels of tyrosine hydroxylase (TH) using immunohistochemistry (IHC). Only animals with a TH-depletion of $>70 \%$ of the striatal area compared with unlesioned side were included in the analyses. If not indicated otherwise, treatment of L-DOPA $(20 \mathrm{mg} / \mathrm{kg}) /$ benserazide $(12 \mathrm{mg} / \mathrm{kg})$ was administered intraperitoneally over 7 consecutive days, starting 3 weeks after the lesion. Drugs were dissolved in physiological saline and administered at the volume of $10 \mathrm{ml} / \mathrm{kg}$ body weight.

\section{Sample preparation and Western blot analysis}

All animals were killed by decapitation and brains were rapidly dissected. Tissue samples were snap-frozen in liquid nitrogen. Tissues were lysed in $1 \%$ SDS (plus phosphatase inhibitors), sonicated for $3 \times 10 \mathrm{~s}$, boiled, and cleared by centrifugation for $20 \mathrm{~min}$ at 13,000 rpm. Protein concentration was determined with a bicinchoninic acid (BCA) kit (Pierce). Thirty to $40 \mu \mathrm{g}$ of protein per well were used for SDS-PAGE, proteins were transferred onto nitrocellulose, incubated with antibodies overnight, and detected by enhanced chemiluminescence. Quantification was performed using ImageJ software.

\section{Immunohistochemistry}

Thirty minutes after the last intraperitoneal injection, animals were anesthetized with pentobarbital/ phenytoin and transcardially perfused with $50 \mathrm{ml}$ of $4 \%$ paraformaldehyde (PFA) in PBS. Brains were incubated overnight in sucrose and sliced at a thickness of $40 \mu \mathrm{M}$. Incubations with antibodies and analysis were performed as described previously (Alcacer et al., 2012). Sections were mounted using Prolong Gold (Invitrogen). Confocal microscopy was performed using a Zeiss LMS 710 laserscanning confocal microscope using the same adjustments for all the sections in a given experiment. For all immunohistochemical analysis, cells were counted manually (in $425 \times 425 \mu \mathrm{m}$ confocal images) and 
averaged from three slices per animal (unlesioned and lesioned sides under blind conditions concerning the mouse genotype and treatment). TH immunofluorescence intensity was quantified in striata with MacBiophotonics ImageJ, and the data represented as mean gray levels above background value.

\section{Cylinder test}

The anti-akinetic effect of L-DOPA was assessed using the cylinder test of forelimb paw placement. Mice were placed in a glass cylinder $(10 \mathrm{~cm}$ wide $\times 14 \mathrm{~cm}$ high) and recorded for $4 \mathrm{~min}$. The number of supporting paw placements performed independently with the left and right paw was counted. The limb use asymmetry score was calculated by expressing the number of wall contacts performed with the forelimb contralateral to lesion as a percentage of total wall contacts (Lundblad et al., 2002). For tests performed with escalating doses of L-DOPA, the mice were tested with 5-7 d intertrial intervals.

\section{Abnormal involuntary movements}

Abnormal involuntary movements (AIMs) were evaluated by an observer blind to the genotype, starting $20 \mathrm{~min}$ after administration of L-DOPA/benserazide ( \pm additional drugs as described). Abnormal movements, clearly distinct from natural or stereotypic behaviors (i.e., grooming or sniffing), were classified into four different subtypes as described previously (Lundblad et al., 2005): locomotive [tight contralateral turns (LOC)], axial (contralateral dystonic posture of the neck and upper body), limb (jerky, fluttering movements of the limb contralateral to the lesion), and orofacial (vacuous jaw movements, tongue protrusions) AIMs. Each subtype was scored on a severity scale from 0 to 4 : 0 , absent; 1 , occasional; 2 , frequent; 3 , continuous; 4 , continuous and not interruptible by external stimuli. The total AIMs score corresponded to the sum of individual scores for each AIM subtype. A composite score was obtained by the addition of scores for axial, limb, and orofacial AIMs (ALO score). The ALO score is considered to more closely reflect the human dyskinetic behavior than the locomotive AIMs score (LOC score).

\section{Experimental design and statistical analysis}

Male mice were used for all experiments except for the experiment using L-DOPA and caffeine in which females were used.

\section{Experiment 1: lesion and response to acute and chronic $L-D O P A$} Separate cohorts of mice were lesioned by injection of 6-OHDA into the dorsolateral striatum as described above.

Cylinder test. One cohort of Drd1a-Cre/CK2 ${ }^{\mathrm{KO}}$ and one cohort of Drd2-Cre/CK2 ${ }^{\mathrm{KO}}$ and their WT littermates were tested in the cylinder test to determine the responsiveness to L-DOPA. Successively higher L-DOPA doses $(2,5$, and $10 \mathrm{mg} / \mathrm{kg}$, combined with benserazide, $12 \mathrm{mg} / \mathrm{kg}$ ) were injected intraperitoneally. Injections were performed every 5-7 d. Mice were tested in the cylinder test $60 \mathrm{~min}$ after injection. Mice were either killed by rapid decapitation, tissue was quickly dissected and lysed for use in Western blotting (anti-TH antibody; 1:1000), or perfused with $4 \%$ PFA for IHC (anti-TH antibody 1:500 in PBST, overnight) as described above.

Chronic L-DOPA treatment. One cohort of Drd1a-Cre/CK2 ${ }^{\mathrm{KO}}$ and one cohort of Drd2-Cre/ CK2 ${ }^{\mathrm{KO}}$ and their WT littermates were used to test the effect of chronic L-DOPA ( $20 \mathrm{mg} / \mathrm{kg} /$ benserazide $12 \mathrm{mg} / \mathrm{kg}$, i.p., $7 \mathrm{~d}$ ) on LID. One day after AIMs assessment (performed as described above), mice were reinjected and killed 30 min thereafter, either by decapitation, quick tissue dissection, and lysis for use in Western blotting (anti-TH, anti- $\mathrm{G}_{\mathrm{olf}}$, anti-tubulin), or perfused with 4\% PFA for IHC using anti-TH (1:1000), anti-pERK (1:300), anti-c-fos (1:300), and anti-PKA phosphosubstrate antibodies (1:200; all in PBS, 1\% serum, overnight). IHC analysis was also performed using anti-pERK and anti-choline-acetyltransferase (ChAT; 1:200 in PBS) antibodies.

To ascertain in which striatal cell type phosphorylation occurs, the Drd1a-Cre/CK2 ${ }^{\mathrm{KO}}$ was bred with a transgenic Drd1a-GFP line for at least six generations where the GFP allele was kept in a heterozygous state. Using these mice, the same chronic L-DOPA experiment was per- formed for IHC analysis using anti-GFP antibody (1:500) in addition to the phosphospecific antibodies mentioned above.

Slices from three animals per genotype (of Drd1a-Cre/CK2 ${ }^{\mathrm{KO}}$ or Drd2-Cre/CK2 ${ }^{\mathrm{KO}}$ mice and their WT littermates) were probed with antiCK2 $\alpha$ (1:400 in PBS) and anti-ChAT antibodies (1:200 in PBS) to determine whether CK2 $\alpha$ knock-out occurs in ChAT-positive cells; for both lines $\sim 100 \mathrm{ChAT}+$ cells were counted per genotype.

To ensure specificity of the anti-enkephalin antibody, we stained slices from Drdla-GFP/Drd1a-Cre/CK2 ${ }^{\mathrm{KO}}$ mice (1:150 in PBS, $1 \%$ horse serum, overnight). If the antibody was specific, then no signal was to be expected in GFP-expressing cells. Once this was confirmed, we stained slices from the chronically L-DOPA-treated Drd2-Cre/CK2 ${ }^{\mathrm{KO}}$ and WT cohort with this antibody to determine whether pERK occurs in indirect projection neurons. Per animal on average 57 Enk + cells in the dorsal, dorsolateral and mediolateral striatum were unambiguously identified using $z$-stacks.

In another variation of this experiment, a Drd2-Cre/CK2 ${ }^{\mathrm{KO}} / \mathrm{WT}$ 6-OHDA lesioned cohort was used for chronic caffeine/L-DOPA coadministration and AIMs assessment. Caffeine, $(2 \mathrm{mg} / \mathrm{kg}$, i.p.), coadministered with a high dose of $20 \mathrm{mg} / \mathrm{kg}$ L-DOPA did not alter LID scores. We therefore tested a low dose of L-DOPA (caffeine $2 \mathrm{mg} / \mathrm{kg}$; L-DOPA 2 $\mathrm{mg} / \mathrm{kg} /$ benserazide $12 \mathrm{mg} / \mathrm{kg}$ ). To determine whether altered LID in the caffeine-treated Drd2-Cre/CK2 2 KO/WT cohort correlated with reduced pERK, immunohistochemical analysis was performed using slices derived from the above cohort treated with caffeine $2 \mathrm{mg} / \mathrm{kg}$; L-DOPA 2 $\mathrm{mg} / \mathrm{kg} /$ benserazide $12 \mathrm{mg} / \mathrm{kg}$, perfused $30 \mathrm{~min}$ after injection.

For all analyses (behavioral and IHC), except for Fig. 1, animals with a $\mathrm{TH}$ depletion $>70 \%$ in the DL striatal area compared with unlesioned side were excluded.

Acute L-DOPA treatment. A separate cohort of 6-OHDA lesioned Drd1a-Cre/Drd1-GFP/CK2 ${ }^{\mathrm{KO}}$ and WT mice was acutely treated with L-DOPA (20 mg/kg, i.p./benserazide $12 \mathrm{mg} / \mathrm{kg}$, i.p.) and perfused $30 \mathrm{~min}$ thereafter. The same antibodies were used for IHC as in the chronic cohort. Similarly, a separate cohort of Drd2-Cre/CK2 ${ }^{\mathrm{KO}}$ and WT mice was lesioned and acutely treated with L-DOPA, before perfusion $30 \mathrm{~min}$ thereafter, followed by IHC.

Statistical analysis. Statistical analysis was performed using two-way ANOVA with Bonferroni's post hoc comparisons for cylinder tests and unpaired Student's $t$ tests for Western blot and IHC comparisons of Figure 1. Statistical significance was set at $p=0.05$ for this and all following experiments. Data are presented as mean \pm SEM for all figures.

Statistical analyses of AIMs behavior were performed using Student's $t$ test for (Fig. 2A-F) and two-way ANOVA with Newman-Keuls post hoc comparisons for the time course experiments (Fig. 2D, G). For IHC analyses of phosphorylation status (pERK, pPKA substrate) and c-fos, two-way ANOVA with Tukey's post hoc comparisons was used when two genotypes (WT/KO) and treatment (unlesioned/lesioned) were compared.

Unpaired two-tailed Student's $t$ test was used when WT was compared with $\mathrm{KO}$ independently of treatment (Figs. 4D, 5G, 6D).

\section{Experiment 2: haloperidol-induced catalepsy}

The catalepsy in response to haloperidol was tested in unlesioned animals of Drd1a-Cre/CK2 ${ }^{\mathrm{KO}}$ and Drd2-Cre/CK2 ${ }^{\mathrm{KO}}$ lines. Before the test, mice were injected intraperitoneally with $0.75 \mathrm{mg} / \mathrm{kg}$ haloperidol [dissolved with $3 \%$ acetic acid in saline, $\mathrm{pH}$ adjusted to 5.2 with $\mathrm{NaOH}(1 \mathrm{M})$ and sonicated for $10 \mathrm{~min}$ ]. Mice were tested 30, 60, 90, and $120 \mathrm{~min}$ after injection. Catalepsy was assessed by gently placing the paws of the mice on a $4.5 \mathrm{~cm}$ high plastic bar of $3 \mathrm{~mm}$ diameter. The latency of the mice staying on the bar with both forelimbs extended was measured. Catalepsy was considered to end when both forelimbs were removed from the bar or when the mice engaged in exploratory behavior (strong head movements). A cutoff time of 5 min was imposed.

To determine a potential involvement of the adenosine receptor family, we coadministered caffeine $(0.5 \mathrm{mg} / \mathrm{kg}$, in saline $)$ or saline alone with haloperidol $(0.75 \mathrm{mg} / \mathrm{kg})$ to the Drd2-Cre/CK2 ${ }^{\mathrm{KO}} / \mathrm{WT}$ cohort and tested mice 30 min thereafter.

Statistical analysis. Two-way ANOVA with Tukey's post hoc comparisons. 
A

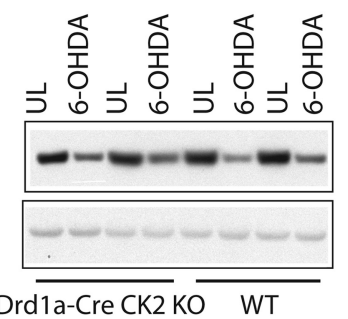

D

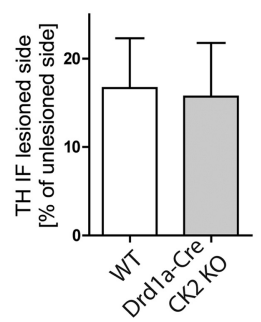

G

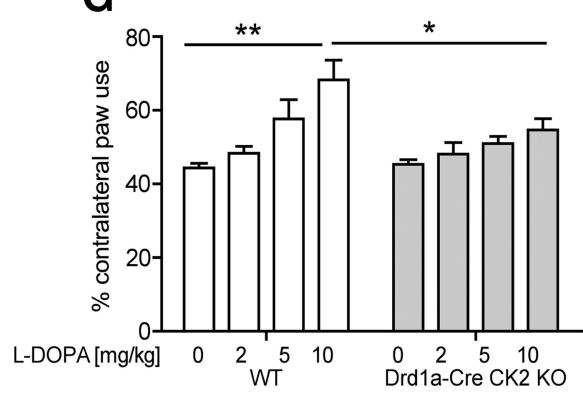

B

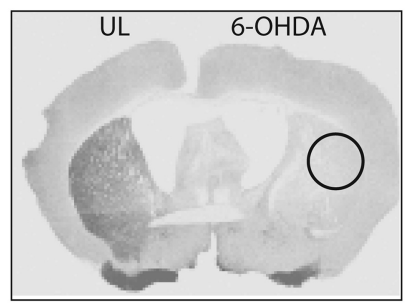

$\mathbf{E}$

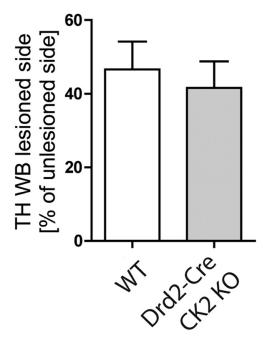

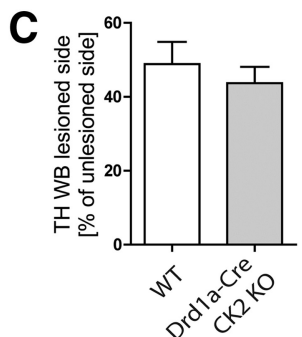

$\mathbf{F}$

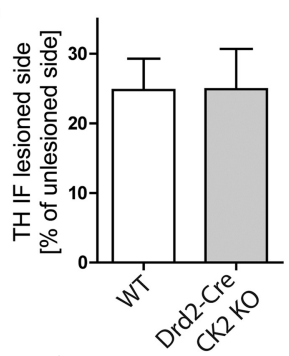

H

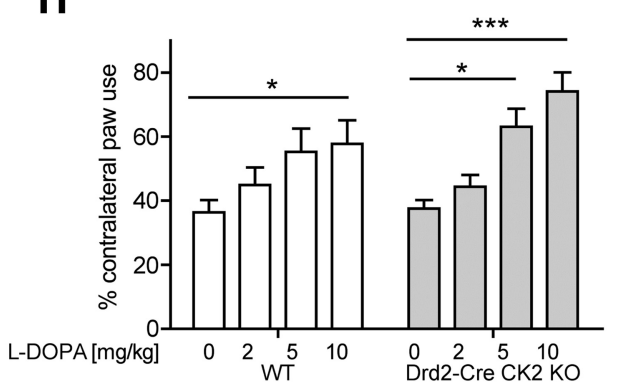

Figure 1. 6-OHDA lesion of conditional CK2 $\alpha$ KO mice. Total striatal protein lysates (30 $\mu \mathrm{g})$ from Drd1a-Cre/CK2 ${ }^{\mathrm{K} 0}$ and control 6-OHDA lesioned mice were separated by SDS/PAGE. Immunoblotting analysis with anti-TH antibody was performed and quantified $(\boldsymbol{A}, \boldsymbol{C})$. Another cohort of animals was used for immunohistochemical analysis using anti-TH antibody (B). Quantification derived from ImageJ density measurements is shown (D). Western blotting and IHC analysis for WT and Drd2-Cre/CK2 ${ }^{\mathrm{K} 0}$ knock-out is depicted in $(\boldsymbol{E})$ and $(\boldsymbol{F})$, respectively. The anti-akinetic responses to augmenting doses of L-DOPA were measured in the cylinder test for Drd1a-Cre/CK2 ${ }^{\mathrm{K} 0} / \mathrm{WT}(\boldsymbol{G})$ and Drd2-Cre/CK2 ${ }^{\mathrm{K} 0} / \mathrm{WT}(\boldsymbol{H})$. Data are mean $\pm \mathrm{SEM}$. ${ }^{*} p<0.05$, ${ }^{* *} p<0.01,{ }^{* * *} p<0.001$. $n=11-12(\boldsymbol{C}), n=13-15(\boldsymbol{D}), n=15-17(\boldsymbol{E}), n=16(\boldsymbol{F}), n=10-11(\boldsymbol{G}), n=9-10(\boldsymbol{H})$.

\section{Experiment 3: effect of CK2 inhibitor CX4945}

For this experiment, 4- to 5-month-old WT male mice (C57BL/6J) were used. Mice were injected with CX4945 (in $0.9 \%$ saline) and killed 30 or 120 min thereafter. To preserve the phosphorylation status of proteins, mice were quickly decapitated and heads dipped in liquid nitrogen until frozen before dissection and lysis in $1 \%$ SDS plus phosphatase inhibitors. Tissue was sonicated $3 \times$ for $10 \mathrm{~s}$ and boiled for $5 \mathrm{~min} .40 \mu \mathrm{g}$ of lysates, quantified by the BCA assay, were separated by SDS-PAGE and phosphorylation levels of pS473Akt and pS129Akt assessed by Western blotting. Three experiments were performed with two animals per treatment, one experiment is shown. For the AIMs assessment, a cohort of WT mice was lesioned by 6-OHDA injection into the medial forebrain bundle as described, and chronically treated for $10 \mathrm{~d}$ with L-DOPA $(3 \mathrm{mg} / \mathrm{kg}) /$ benserazide $(10 \mathrm{mg} / \mathrm{kg})$. On day 11 CX4945 (100 mg/kg, i.p.), was preinjected 15 min before L-DOPA administration and AIMs scored.

Statistical analysis. Two-way ANOVA.

\section{Results}

\section{Effects of 6-OHDA lesion in Drd1a-Cre/CK2 ${ }^{\mathrm{KO}}$ and Drd2-Cre/ CK2 $2^{\mathrm{KO}}$ mice}

To generate a hemi-parkinsonian rodent model, we applied unilateral striatal 6-OHDA lesions to conditional CK2 knock-out mice where CK2 had been ablated by crossing cell type-specific Cre driver lines (Drd1a-Cre ${ }^{+/-}$or Drd2-Cre ${ }^{+/-}$) with CK2 $\alpha^{\text {loxP/loxP }}$ mice. Drd1a-Cre ${ }^{-1-}$ or Drd2-Cre ${ }^{-1-}$ littermates served as controls. We first asked whether the sensitivity to 6-OHDA may be affected by the conditional knock-out of CK2. To this end, we measured the striatal expression of $\mathrm{TH}$ in both hemispheres of
6-OHDA-lesioned mice using Western immunoblotting (Fig. $1 A, C, \mathrm{E}$ ) or IHC (Fig. $1 B, D, \mathrm{~F}$ ). We did not detect any significant differences in $\mathrm{TH}$ expression between the two types of $\mathrm{KO}$ animals and WT controls by Western immunoblotting or IHC ( $p>$ 0.05 for all); neither did we observe a difference in survival rates after lesion between the genotypes. To ascertain lesion severity using a behavioral endpoint, we assessed asymmetries in spontaneous forelimb use in the cylinder test (where the degree of limb use asymmetry correlates with the severity of striatal DA denervation; Boix et al., 2015). The 6-OHDA lesion induced a similar reduction in contralateral forelimb use in all genotypes (Fig. $1 G, H$; at baseline).

We next asked whether the disuse of the parkinsonian limb could be ameliorated with a therapeutic dose of L-DOPA (Francardo et al., 2011). Mice were thus tested $1 \mathrm{~h}$ after the administration of L-DOPA $(2,5$, and $10 \mathrm{mg} / \mathrm{kg})$. This treatment dose-dependently improved limb use asymmetry in the WT controls of both KO lines (Fig. $1 G, H$, empty bars; $p<0.01$ for the highest L-DOPA dose vs vehicle in the WT of the Drdla-Cre/ $\mathrm{CK} 2{ }^{\mathrm{KO}}$ and $p<0.05$ for the highest L-DOPA dose vs vehicle in the WT of the Drd2-Cre/CK2 ${ }^{\mathrm{KO}}$ ). When treated with L-DOPA, Drd1a-Cre/CK2 ${ }^{\mathrm{KO}}$ mice showed a trend toward increased contralateral paw use, but the effect did not reach significance. Accordingly, the percentage of contralateral limb use with $10 \mathrm{mg} / \mathrm{kg}$ L-DOPA was significantly lower in Drd1a-Cre/CK2 ${ }^{\mathrm{KO}}$ mice relative to their WT controls (Fig. $1 G ; p<0.05$ ). The main effect of 
A

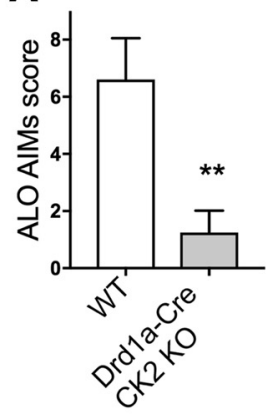

E

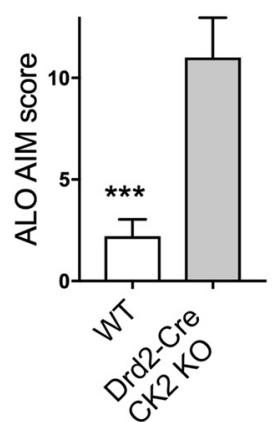

B

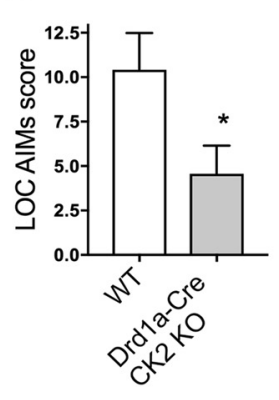

$\mathbf{F}$

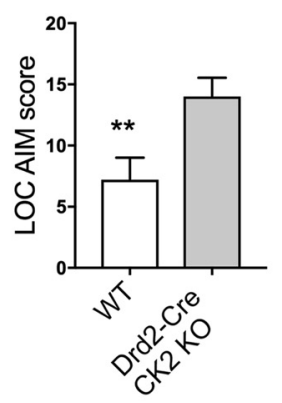

C

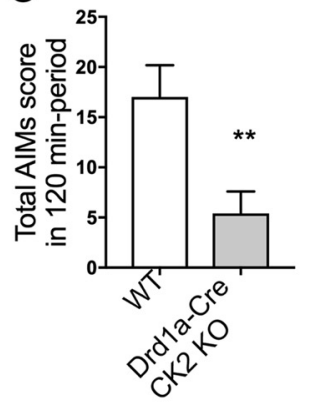

G

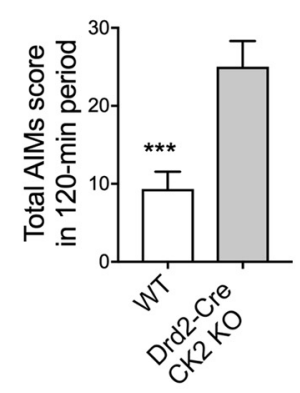

D

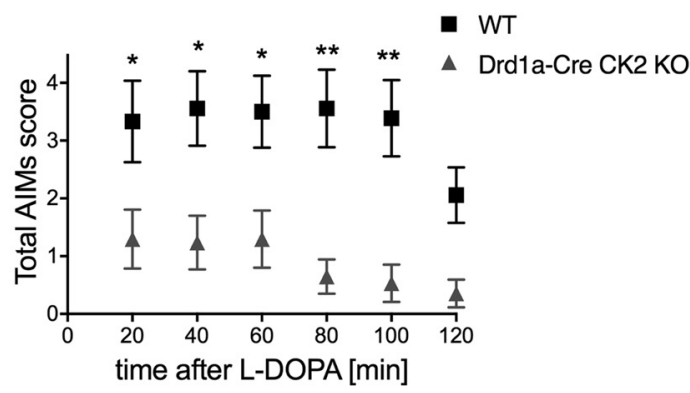

$\begin{array}{ll}\text { H } & \text { WT } \\ & \Delta \text { Drd2-Cre CK2 KO }\end{array}$

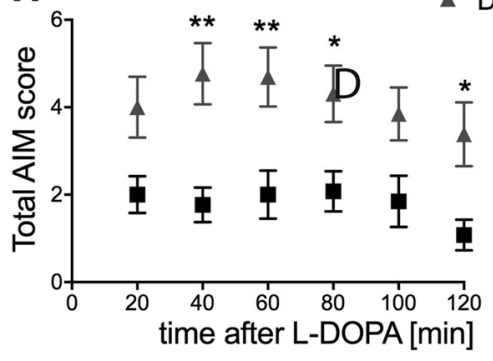

Figure 2. LID in conditional CK2 $\alpha$ K0 mice. Drd1a-Cre/CK2 ${ }^{\mathrm{K} 0}$ and Drd2-Cre/CK2 ${ }^{\mathrm{K} 0}$ and corresponding WT littermates were treated with L-DOPA/benserazide for $7 \mathrm{~d}$. ALO score $(\boldsymbol{A}, \boldsymbol{E})$, LOC score $(\boldsymbol{B}, \boldsymbol{F})$, and total AlMs scores were determined and plotted as summarized score $(\boldsymbol{C}, \boldsymbol{G})$ or as time course at $20 \mathrm{~min}$ intervals for $2 \mathrm{~h}$ after L-D0PA injection $(20 \mathrm{mg} / \mathrm{kg} ;$ benserazide $12 \mathrm{mg} / \mathrm{kg}$, i.p.; $\boldsymbol{D}, \boldsymbol{H})$. Data are mean \pm SEM. ${ }^{*} p<0.05,{ }^{* *} p<0.01,{ }^{* *} p<0.001 . n=17-18(\boldsymbol{A}-\boldsymbol{D}), n=13-15(\boldsymbol{E}-\boldsymbol{H})$.

dose was significant: $F_{(3,57)}=10.64, p<0001$; and the main effect of genotype was at the cusp of significance: $F_{(1,57)}=4.33, p=$ 0.05 . Mice with CK2 knock-out in D2-MSNs showed a response to L-DOPA and their performance was significantly improved already at the dose of $5 \mathrm{mg} / \mathrm{kg}(p<0.05)$, whereas the effect of this dose was not significant in WT littermates (Fig. $1 H$ ). After treatment with $10 \mathrm{mg} / \mathrm{kg}$ L-DOPA, contralateral forelimb use tended to be larger in Drd2-Cre/CK2 ${ }^{\mathrm{KO}}$ mice relative to their WT controls (Fig. $1 H$ ), but this difference did not reach significance. The main effect of dose was significant: $F_{(3,45)}=15.04, p<0001$; and the main effect of genotype did not reach significance: $\left(F_{(1,45)}=\right.$ $1.66, p=0.21)$.

\section{Dyskinesia is reduced in Drd1a-Cre/CK2 ${ }^{\mathrm{KO}}$ and enhanced Drd2-Cre/ CK2 ${ }^{\mathrm{KO}}$ mice}

It is well established that 6-OHDA-lesioned mice rapidly develop AIMs when treated with L-DOPA (Francardo et al., 2011), and ALO AIMs provide a valid behavioral measure of LID in this animal model (Lundblad et al., 2005; Francardo et al., 2011). 6-OHDA-lesioned $\mathrm{KO}$ mice were treated for $7 \mathrm{~d}$ with a dose of L-DOPA sufficient to induce AIMs $(20 \mathrm{mg} / \mathrm{kg}$; Lundblad et al., 2005), and a dyskinesia rating session was performed on the last day of treatment. ALO scores were significantly lower in DrdlaCre/ $\mathrm{CK} 2{ }^{\mathrm{KO}}$ than in WT (Fig. $2 A ; p=0.005$ ). LOC scores, which correlate with the extent of contralateral rotation (Lundblad et al., 2002), were also significantly lower (Fig. $2 B ; p=0.036$ ). Accordingly, the total AIM score was significantly reduced in Drd1aCre/ $\mathrm{CK} 2{ }^{\mathrm{KO}}$ compared with controls. This was apparent both on the sum of AIM scores per session (Fig. $2 C$; $p=0.006$ ) and when comparing the AIM scores per monitoring period (Fig. 2D), the main effect of genotype was significant: $F_{(1,198)}=56.35, p<$ 0.0001 .
The development of LID was studied also in Drd2-Cre/CK2 ${ }^{\mathrm{KO}}$ mice using the same experimental design. After $7 \mathrm{~d}$ of treatment with L-DOPA $(20 \mathrm{mg} / \mathrm{kg} / \mathrm{d})$, ALO AIM scores were significantly elevated in the $\mathrm{KO}$ mice compared with their controls (Fig. 2E; $p=0.0002$ for $\mathrm{KO}$ vs controls). In addition, locomotive scores (Fig. $2 F ; p=0.0092$ ) and total scores differed significantly between $\mathrm{KO}$ and controls (Fig. $2 G$ ), $p=0.0004$. When total AIM scores per monitoring period were compared (Fig. $2 \mathrm{H}$ ), there was a main effect of genotype: $F_{(1,144)}=49.79, p<0.0001$. These data show that, $\mathrm{KO}$ of $\mathrm{CK} 2$ in D1 and D2 receptor-expressing cells has opposing effects on LID development in the 6-OHDA lesion model.

ERK but not PKA substrate phosphorylation is reduced in the dopamine-depleted striatum of Drd1a-Cre/CK2 ${ }^{\mathrm{KO}}$ mice after chronic L-DOPA

Treatment with L-DOPA activates ERK signaling in the DAdepleted striatum (Gerfen et al., 2002; Pavón et al., 2006), and the levels of phosphorylated ERK correlate with dyskinesia severity (Westin et al., 2007). It was further shown that ERK-dependent plasticity is responsible for the aberrant response to chronic L-DOPA (Cerovic et al., 2015). Moreover, inhibition of striatal ERK signaling improves LID (Santini et al., 2007; Fasano et al., 2010). We used IHC and confocal microscopy to examine the cellular expression of pERK in the dorsolateral striatum. We first used Drd1a-Cre/CK2 ${ }^{\mathrm{KO}}$ mice crossed with the Drd1a-GFP-reporter mouse line to verify that L-DOPA-induced pERK occurs in D1 but not D2 neurons, as previously reported in this animal model of LID (Santini et al., 2009). The induction of pERK by L-DOPA in GFP-positive cells was significantly attenuated in Drd1a-Cre/ $\mathrm{CK} 2{ }^{\mathrm{KO}}$ mice compared with control mice, expressed as percent- 
age of pERK-positive D1 projection neurons as well as the average total number of pERK-positive+ cells per image (Fig. 3A-C), correlating with a behavioral phenotype of reduced dyskinesia severity. Statistically, there was an interaction genotype $\times$ treatment for the percentage of pERK in GFP + cells $\left(F_{(1,27)}=7.3915\right.$, $p=0.011)$. Adjacent coronal sections were immunostained for c-Fos, a marker of immediate-early genes induced by L-DOPA in DA-depleted striata. Another set of sections was immunostained using an antibody that recognizes the phosphorylated form of the PKA consensus substrate peptide, which provides an indirect estimate of PKA activity (Alcacer et al., 2012). We did not detect significant differences between WT and Drd1a/Cre ${ }^{\mathrm{KO}}$ on either marker (Fig. 3D,E). Statistically, there was no significant interaction genotype $\times$ treatment for $\mathrm{c}$-fos $\left(F_{(1,20)}=0.491, p=\right.$ $0.492)$ or pPKA substrate $\left(F_{(1,26)}=1.236, p=0.276\right)$. When unilaterally lesioned Drd1a/Cre ${ }^{\mathrm{KO}}$ and WT mice are acutely treated with L-DOPA, we observe a strong response in ERK phosphorylation in direct pathway neurons, however, no difference between WT and KO in pERK, c-Fos, and pPKA substrate is detected ( $p>0.05$ for all).

It has been described that ERK phosphorylation also occurs in cholinergic interneurons after chronic (but not acute) L-DOPA administration, and that muscarinic receptor antagonists reduce the development and/or expression of LID both in 6-OHDA lesioned mice and the aphakia mouse model of PD (Ding et al., 2011). We were thus interested in assessing ERK phosphorylation in ChAT-immunoreactive neurons. Drd1a-Cre/CK2 ${ }^{\mathrm{KO}}$ mice showed a much reduced expression of pERK levels in ChAT cells (Fig. $4 A, B$ ), and there was a significant genotype $\times$ treatment interaction $\left(F_{(1,21)}=18.16, p=0003\right)$. To better understand these findings, it was imperative to assess whether CK2 expression in ChAT cells is ablated by Drd1a-Cre or Drd2-Cre. In agreement with published data (Le Moine et al., 1991), we found that CK2 expression is not affected in ChAT cells of Drdla-Cre/ $\mathrm{CK} 2{ }^{\mathrm{KO}}$ mice (Fig. 4C). The percentage of CK2-expressing ChAT cells was determined as $89.4 \%( \pm 1.5 \%)$ for the Drdla-Cre/ CK2 ${ }^{\mathrm{KO}} 88.2 \%( \pm 2.6 \%)$ for the WT mice $(p=0.687$; Fig. $4 D)$.

\section{ERK but not PKA substrate phosphorylation is elevated in the dopamine-depleted striatum of Drd2-Cre/CK2 ${ }^{\mathrm{KO}}$ mice after chronic L-DOPA}

Next, we determined whether pERK levels were affected in the conditional Drd2-Cre/CK2 ${ }^{\mathrm{KO}}$ mice after chronic L-DOPA treatment. Interestingly, the total number of pERK-positive cells in the 6-OHDA-lesioned striatum was twofold larger in Drd2-Cre/ $\mathrm{CK} 2{ }^{\mathrm{KO}}$ mice than WT controls (Fig. $5 A, B$ ). Statistically, there was a genotype $\times$ treatment interaction $\left(F_{(1,54)}=4.478, p=0.039\right)$.

The number of ChAT/pERK-positive neurons did not differ between Drd2-Cre/CK2 ${ }^{\mathrm{KO}}$ and controls (Fig. $5 \mathrm{C}$ ) and the interaction genotype $\times$ treatment was not significant $\left(F_{(1,48)}=0.034\right.$, $p=0.854$ ). An analysis of sections immunostained for c-Fos and PKA phosphosubstrates did also not detect differences between the two genotypes (Fig. $5 D, E$ ), with $F_{(1,45)}=0.853, p=0.361$ and $F_{(1,30)}=0.083, p=0.775$, respectively. We determined that CK2 expression was ablated in ChAT neurons of the Drd2-Cre line, confirming previous data indicating the expression of $\mathrm{D} 2$ receptor in cholinergic neurons (Fig. 5F; Aubry et al., 1993). The percentage of CK2-expressing ChAT cells was quantified as $4.3 \%$ $( \pm 3.1 \%)$ for Drd2-Cre/CK2 ${ }^{\mathrm{KO}}$ and $89.1 \%( \pm 2.1 \%)$ for $\mathrm{WT}$ mice, $p<0.0001 \mathrm{WT}$ versus KO (Fig. 5G). This indicates that pERK is activated in these ChAT-positive neurons despite the absence of CK2.
When unilaterally lesioned Drd2-Cre/CK2 ${ }^{\mathrm{KO}}$ and WT mice were acutely treated with L-DOPA, we did not detect differences between WT and KO in pERK, c-Fos, and pPKA substrate (Fig. 5H-J) or statistically significant interactions (genotype $\times$ treatment).

We determined that in the $\mathrm{Drd} 2 / \mathrm{Cre}^{\mathrm{KO}} 49.0 \%( \pm 1.7 \%)$ of all striatal cells are depleted of $\mathrm{CK} 2 \alpha$, indicating that $\mathrm{CK} 2 \alpha$ is depleted in all D2 striatal neurons (data not shown). We wanted to address whether the enhanced pERK signal occurs in the cells depleted of CK2 or whether, as has been described by others, in D1 striatal projection neurons (Gerfen et al., 2002; Santini et al., 2009). To this end, we stained coronal slices from chronically treated mice with anti-enkephalin antibody, a marker of D2 projection neurons. In tile scans, using this antibody, the staining reflects the in situ data (Allen Brain Atlas, RP_060315_01_A07; Fig. 6A). We were able to identify D2 projection neurons by their lack of GFP expression in slices from Drdla-GFP; Drdla-Cre/ $\mathrm{CK} 2{ }^{\mathrm{KO}}$ mice (Fig. $6 \mathrm{~B}$ ). In slices derived from L-DOPA treated Drd2-Cre/CK2 ${ }^{\mathrm{KO}}$, elevated pERK signal was not detected in D2 projection neurons (Fig. 6C). In WT and Drd2-Cre/CK2 ${ }^{\mathrm{KO}}$ mice no difference in pERK expression was detected: a very low percentage of $2 \%( \pm 1.5 \%)$ and $0.9 \%( \pm 0.3 \%)$ of Enk + cells expressed pERK in WT and Drd2-Cre/CK2 ${ }^{\mathrm{KO}}$, respectively (Fig. $6 D ; p=0.265)$, indicating that the vast majority of ERK phosphorylation must occur in striatonigral neurons. Our findings confirm work by other groups that had shown that these D1Rexpressing striatonigral cells are hyper-responsive to L-DOPA and allow us to conclude that lack of CK2 (in D2 projection neurons) has an indirect, non-cell autonomous effect on D1 neurons (Gerfen et al., 2002).

\section{Haloperidol-induced catalepsy is altered in opposing ways in Drd1a-Cre/CK2 ${ }^{\mathrm{KO}}$ and Drd2-Cre/CK2 ${ }^{\mathrm{KO}}$ mice}

Haloperidol is a prototype of antipsychotic drugs that induce extrapyramidal side effects including catalepsy, manifested as extreme hypolocomotion and rigid immobility (Miyamoto et al., 2005). Haloperidol-induced catalepsy has been proposed to result from inhibition of striatal postsynaptic $\mathrm{D} 2$ receptors resulting in overactivity of the indirect pathway and decreased movement (Boulay et al., 2000). Antagonists of D1-type receptors (e.g., SCH23390) can also induce catalepsy by reducing the activity of direct pathway neurons (Undie and Friedman, 1988).

To test the involvement of CK2 expressed by D1- or D2-positive neurons in this extrapyramidal disorder, we treated Drdla-Cre/ $\mathrm{CK} 2{ }^{\mathrm{KO}}$ and Drd2-Cre/CK2 ${ }^{\mathrm{KO}}$ mice with haloperidol $(0.75 \mathrm{mg} / \mathrm{kg})$ and quantified catalepsy using the standard bar test (Boulay et al., 2000). Drdla-Cre/CK2 $2^{\mathrm{KO}}$ mice removed their forelimbs from the bar almost immediately (Fig. 7A), with a main effect of genotype $\left(F_{(1,54)}=13.49, p=0.0006\right)$. However, in Drd2-Cre/CK2 ${ }^{\mathrm{KO}}$, the latency to leave the bar was strongly enhanced (Fig. $7 B$ ), the main effect of genotype was significant $\left(F_{(1,39)}=58.97, p<0.0001\right)$. $A_{2 \mathrm{~A}}$ antagonists have been shown to counteract catalepsy induced by D1 or D2 receptor antagonists (Hauber et al., 2001). Thus, we hypothesized that the elevated catalepsy in Drd2-Cre/CK2 ${ }^{\mathrm{KO}}$ mice may be mediated by enhanced $A_{2 A}$ signaling. To test this hypothesis, we coadministered haloperidol with the $\mathrm{A} 1 / \mathrm{A}_{2 \mathrm{~A}}$ antagonist, caffeine. This cotreatment abolished the elevated catalepsy in Drd2-Cre/CK2 ${ }^{\mathrm{KO}}$ (Fig. 7C) but had no significant effect on the WT group. Statistically, there was a genotype $\times$ treatment interaction $\left(F_{(1,20)}=20.92, p=0.0002\right)$. We had previously determined that caffeine alone, at a dose of up to $2 \mathrm{mg} / \mathrm{kg}$, does not affect locomotor behavior in these mice. Our results confirm that $\mathrm{A}_{2 \mathrm{~A}} \mathrm{R}$ signaling is elevated in $\mathrm{Drd} 2-\mathrm{Cre} / \mathrm{CK} 2^{\mathrm{KO}}$ mice, 
A

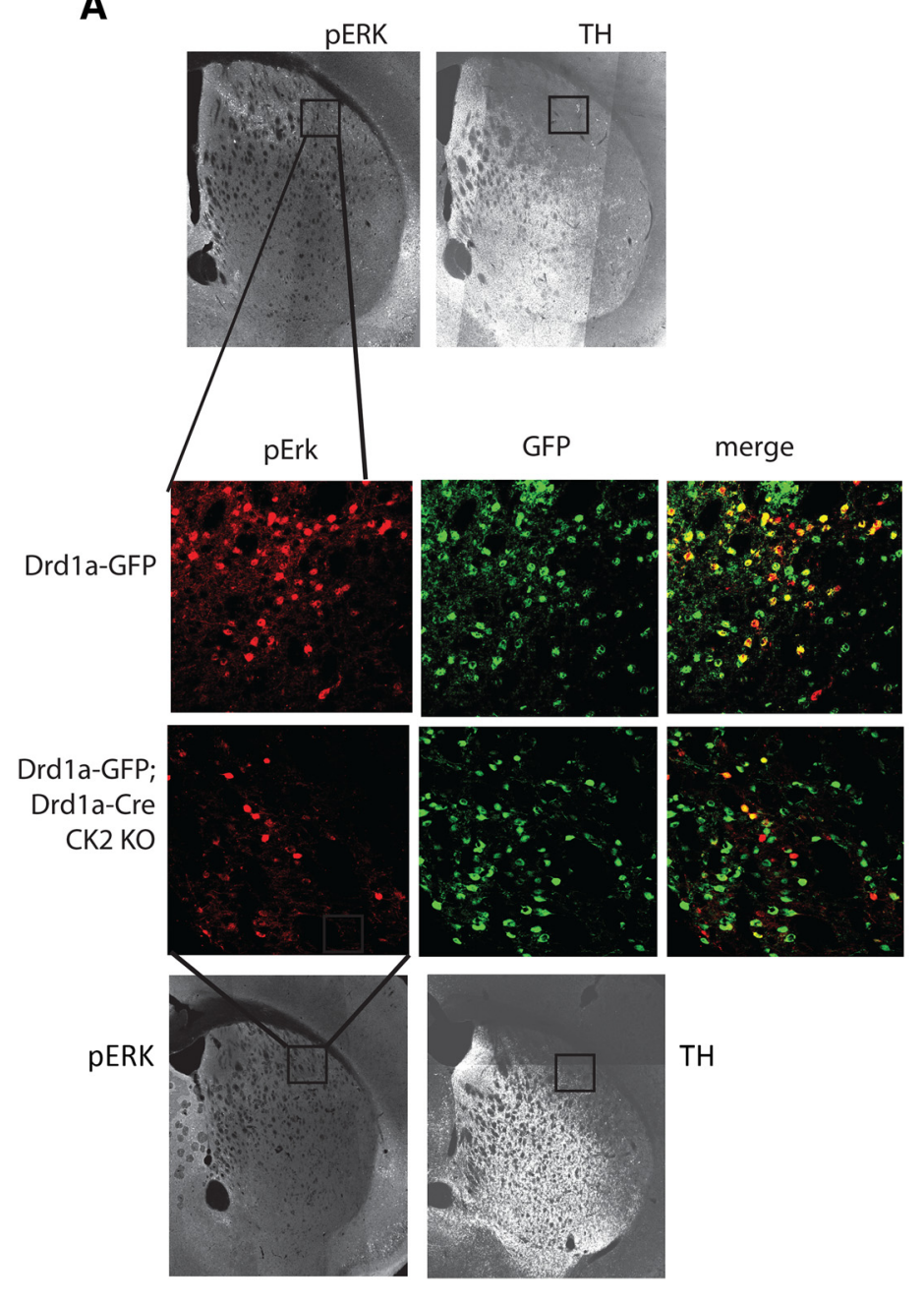

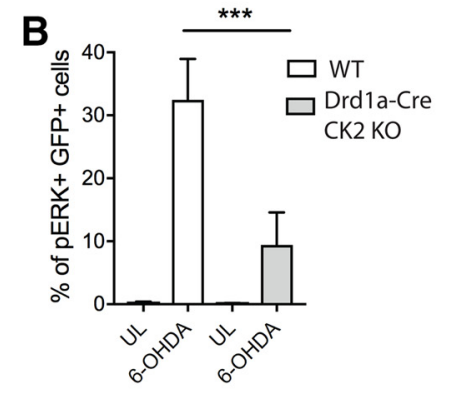

C

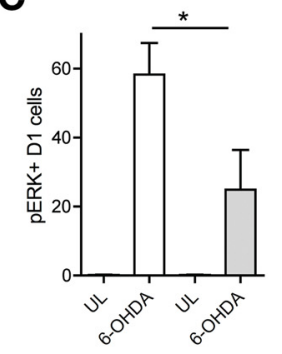

$\mathbf{F}$

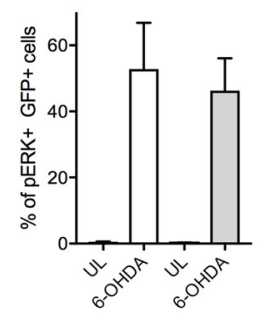

D

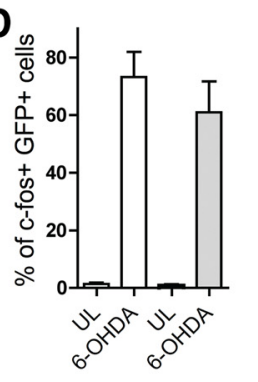

H

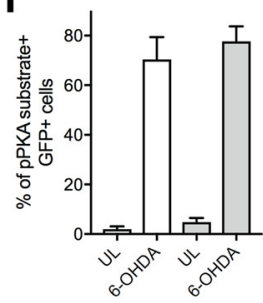

Figure 3. L-DOPA-dependent ERK1/2 phosphorylation in D1-MSNs is reduced in the Drd1-Cre/Drd1a-GFP/CK2 ${ }^{\mathrm{KO}}$ mice. IHC analysis of the dorsolateral striatum (lesioned side) of coronal slices from WT and Drd1-Cre/Drd1a-GFP/CK2 ${ }^{\mathrm{KO}}$ mice after L-DOPA treatment (20 mg/kg; benserazide $12 \mathrm{mg} / \mathrm{kg}$, i.p. for $7 \mathrm{~d}$ ) using pERK antibody (pT202/Y204) and anti-GFP antibody (A). Quantification of immunofluorescence using antibodies directed toward GFP and pERK (B, $\boldsymbol{C}), \boldsymbol{c}-\mathrm{fos}(\boldsymbol{D})$, and pan-pPKA substrate $(\boldsymbol{E})$. Scale bar, $100 \mu \mathrm{m}$. Quantification of immunofluorescence using antibodies directed toward GFP and pERK $(\boldsymbol{F}), c$-fos $(\boldsymbol{G})$, and pan-pPKA substrate $(\boldsymbol{H})$ after acute L-DOPA $\left(20 \mathrm{mg} / \mathrm{kg}\right.$; benserazide $12 \mathrm{mg} / \mathrm{kg}$, i.p.). Data are mean \pm SEM. ${ }^{*} p<0.05,{ }^{* * *} p<0.001 . n=6-7$ $(\boldsymbol{B}-\boldsymbol{E}), n=8-10(\boldsymbol{F}-\boldsymbol{H})$. 
A

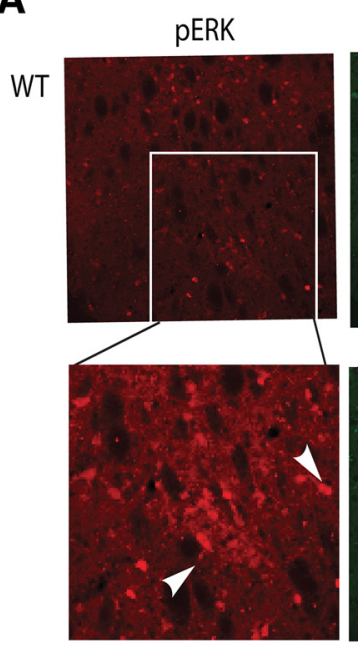

Drd1a-
Cre
CK2 KO
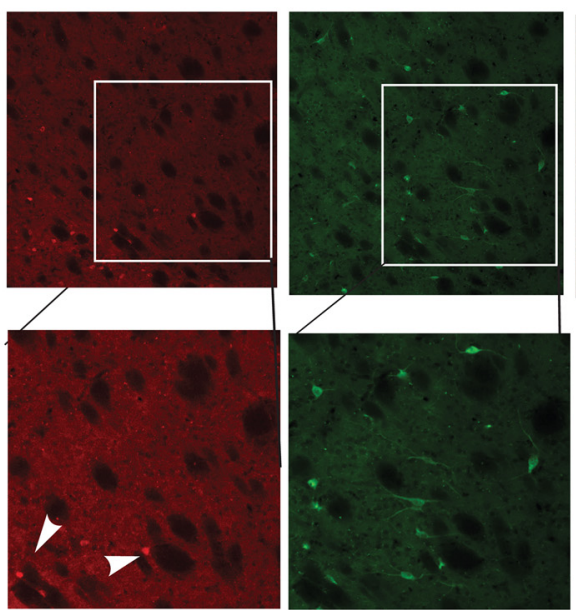

C
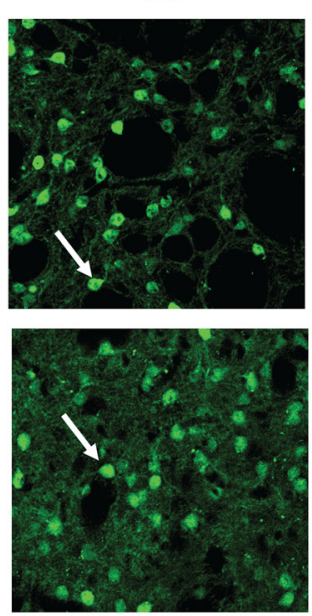

Drd1a-Cre Drd1a-GFP CK2 KO

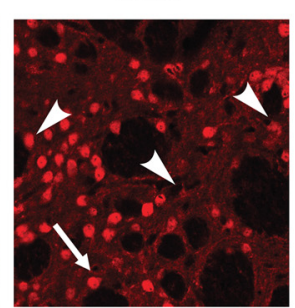

ChAT

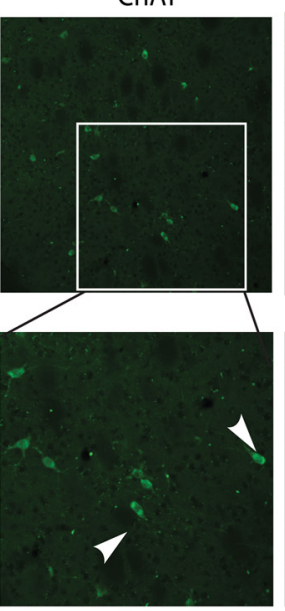

1
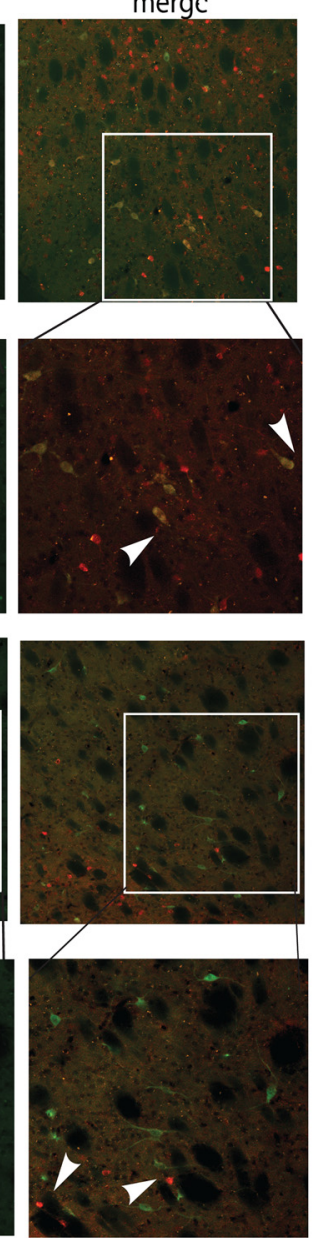

ChAT
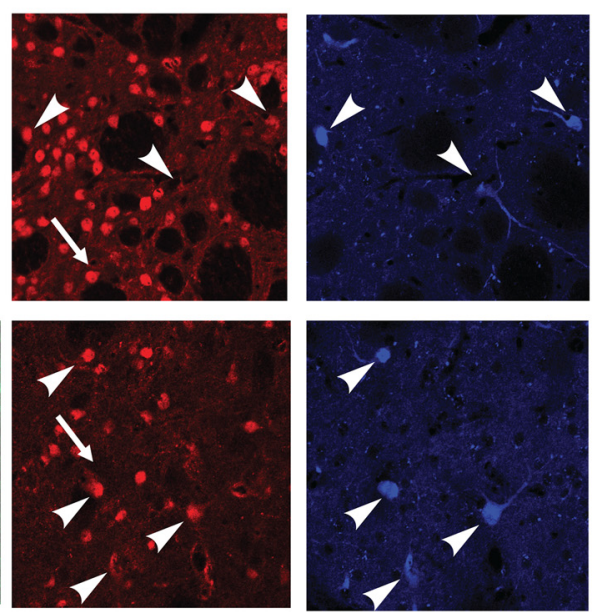

merge

B
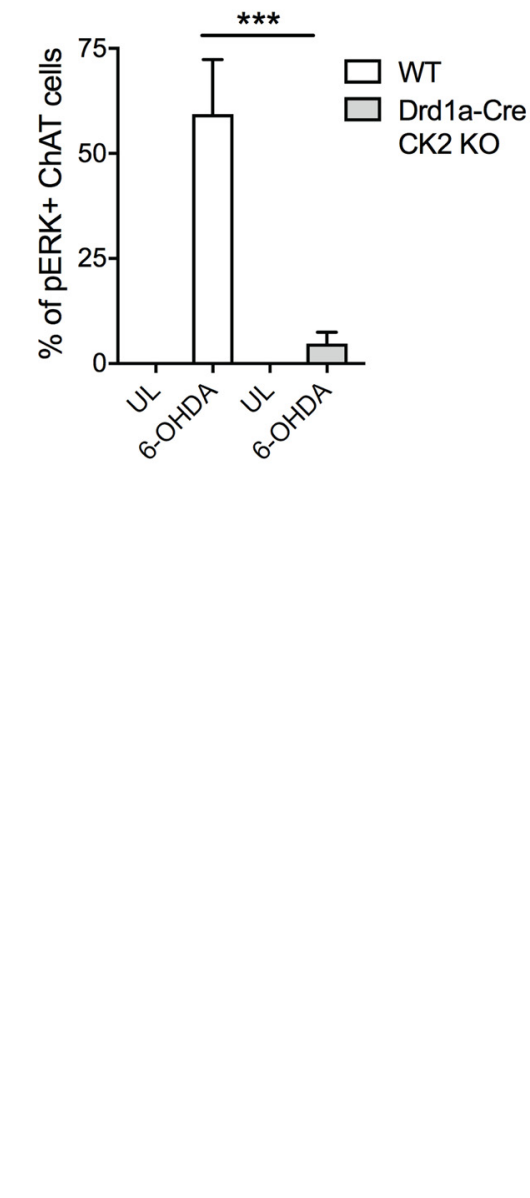

Figure 4. L-DOPA-dependent ERK1/2 phosphorylation in ChAT interneurons is reduced in the Drd 1a-Cre/CK2 ${ }^{\mathrm{K} 0}$ mice. Immunohistochemical analysis of the lesioned dorsolateral striatum of coronal slices from WT and Drd1a-Cre/CK2 ${ }^{\mathrm{K} 0}$ mice after L-DOPA treatment ( $20 \mathrm{mg} / \mathrm{kg}$; benserazide $12 \mathrm{mg} / \mathrm{kg}$, i.p. for $7 \mathrm{~d}$ ) using pERK (pT202/Y204) and ChAT antibodies (A) and quantification thereof (B). Arrows point to pERK + cells. Scale bar, $100 \mu \mathrm{m}$. IHC analysis using anti-CK2 $\alpha$, anti-GFP, and anti-ChAT antibodies of dorsolateral sections of Drd1-Cre/Drd1a-GFP/CK2 ${ }^{\mathrm{KO}} \mathrm{mice}(\boldsymbol{C})$. Representative images are shown, arrowheads point to ChAT neurons and arrow to D1-neurons, 3 animals per genotype were analyzed and quantified (D). Data are mean \pm SEM. ${ }^{* * *} p<0.001 . n=6-7$ (B), $n=3($ D) .

engendering a hyperactivity of indirect pathway neurons. Accordingly, caffeine reduces the haloperidol-induced overactivation of indirect pathway neurons preferentially in the Drd2-Cre/CK $2^{\mathrm{KO}}$, rescuing their phenotype.
Caffeine has anti-dyskinetic effects in Drd2-Cre/CK2 ${ }^{\mathrm{KO}}$ mice

Our results using haloperidol and caffeine prompted the question, whether the enhanced LID score in the Drd2-Cre/CK2 ${ }^{\mathrm{KO}}$ mice may be caused by elevated $\mathrm{A}_{2 \mathrm{~A}} \mathrm{R}$ expression and/or signal- 
A
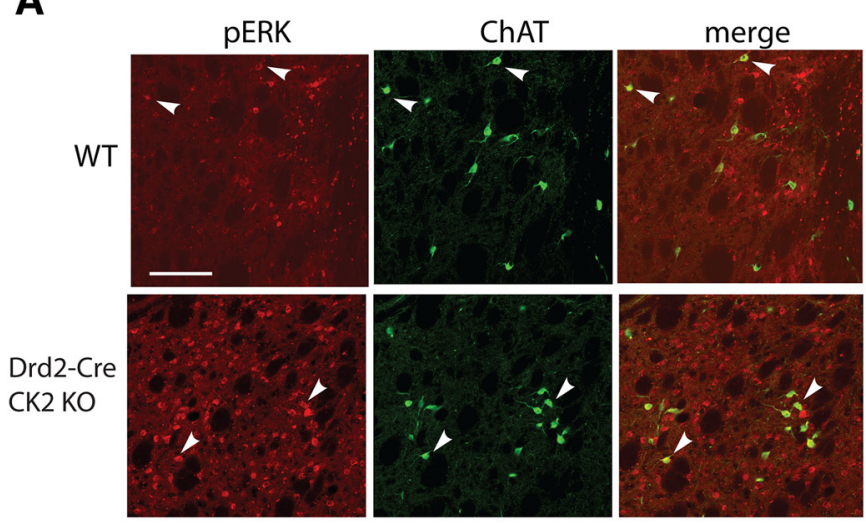

D

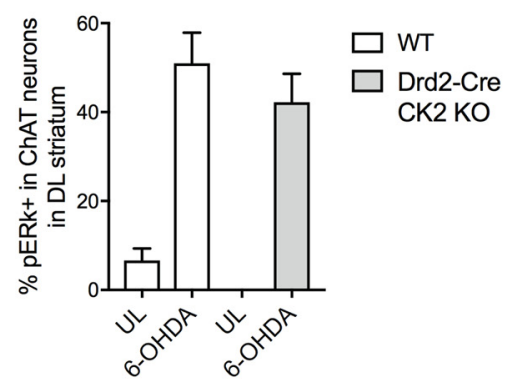

B

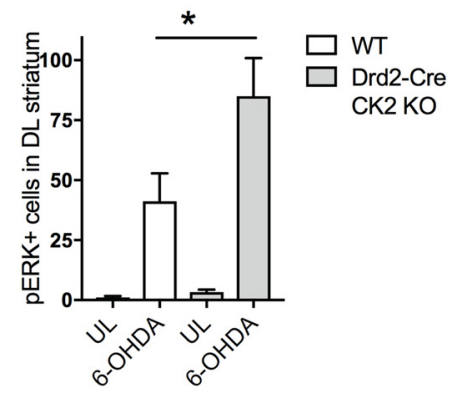

\section{E}
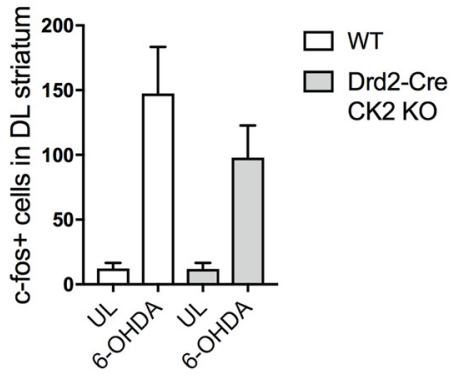

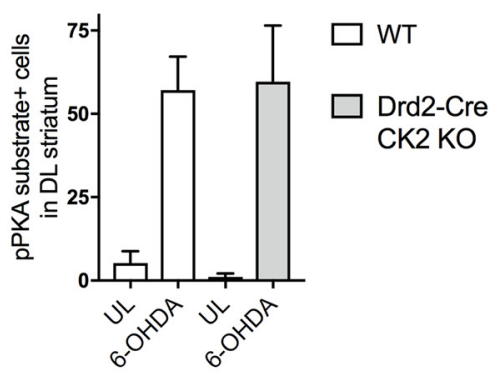

$\mathbf{F}$

WT
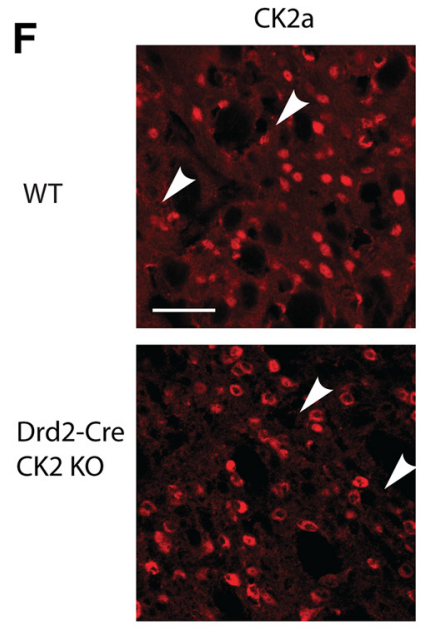

H

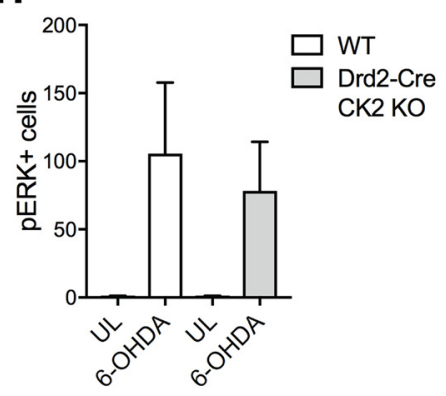

ChAT
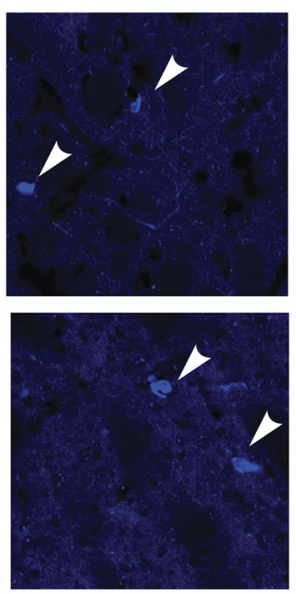
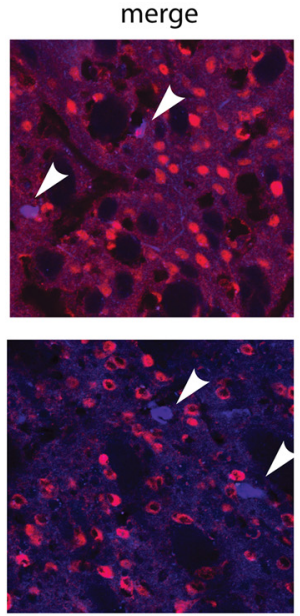

I

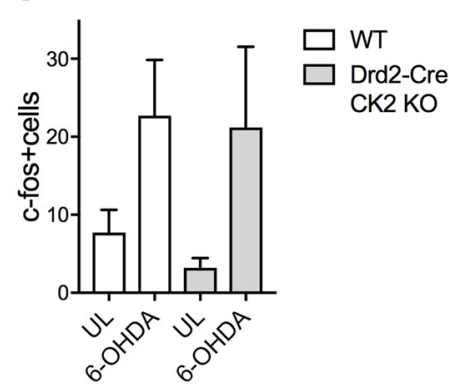

$\mathbf{J}$

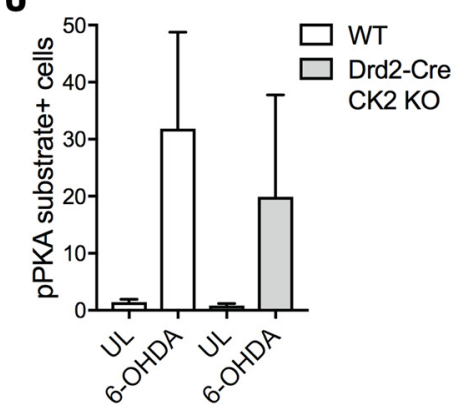

Figure 5. L-DOPA-dependent ERK1/2 phosphorylation is reduced in the Drd2/Cre ${ }^{\mathrm{K} 0}$ mice. IHC analysis of the lesioned dorsolateral striatum of coronal slices from WT and Drd2-Cre/CK2 ${ }^{\mathrm{K} 0}$ mice after L-DOPA treatment (20 mg/kg; benserazide $12 \mathrm{mg} / \mathrm{kg}$, i.p. for $7 \mathrm{~d}$ ) using antibodies against pERK (pT202/Y204) and ChAT, arrowheads point towards pERK + and ChAT + cells (A). Scale bar, 100 $\mu \mathrm{m}$. Quantification of immunofluorescence of pErk1/2-positive cells $(\boldsymbol{B})$. Quantification of immunofluorescence of cells that are positive for pErk $1 / 2$ and ChAT normalized by the total number of ChAT-positive neurons (C). Quantification of cells that are (-Fos-positive (D) or pPKA substrate-positive (E). IHC analysis using anti-CK2 $\alpha$ and anti-ChAT antibodies of dorsolateral sections of $\operatorname{Drd2}-\mathrm{Cre} / \mathrm{CK2}{ }^{\mathrm{K} 0}$ mice. Representative images are shown $(\boldsymbol{F})$, three animals per genotype were analyzed and quantified (G). Quantification of immunofluorescence using antibodies directed toward GFP and pERK $(\boldsymbol{H}), \boldsymbol{c}-$-fos $(\boldsymbol{I})$, and pan-pPKA substrate $(\boldsymbol{J})$ after acute L-DOPA $\left(20 \mathrm{mg} / \mathrm{kg}\right.$; benserazide $12 \mathrm{mg} / \mathrm{kg}$, i.p.). Data are mean \pm SEM. ${ }^{* * * *} p<0.0001 . n=7-8(\boldsymbol{B}-\boldsymbol{E}), n=3(\boldsymbol{G}), n=5-7$ $(\boldsymbol{H}-\boldsymbol{J})$. 
A

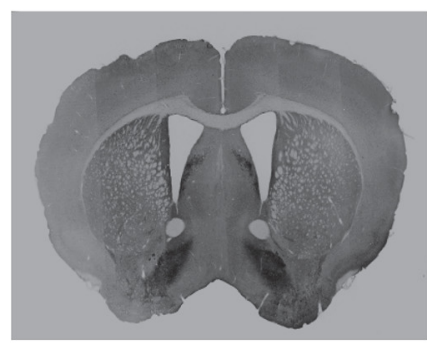

B

Enk
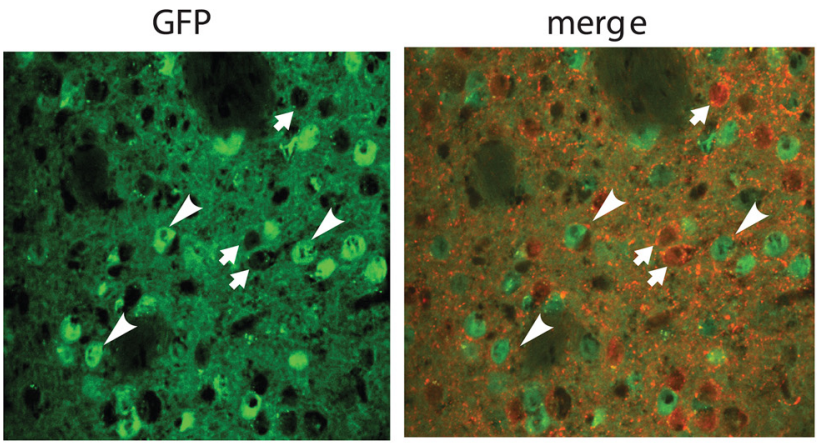

C

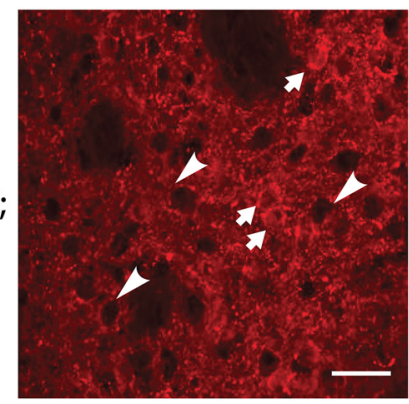

Drd1a-GFP

Drd1a-Cre

CK2 KO

pERK

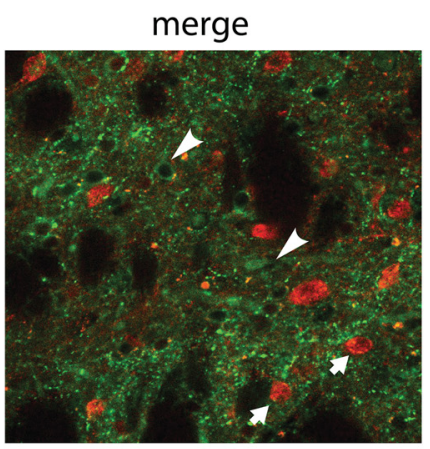

Enk

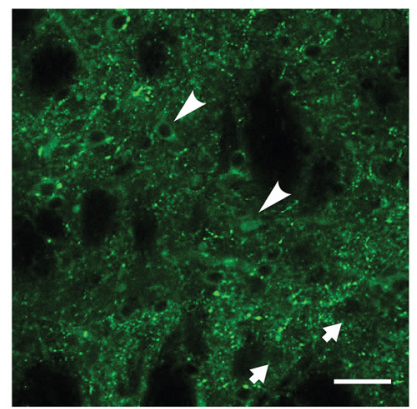

WT
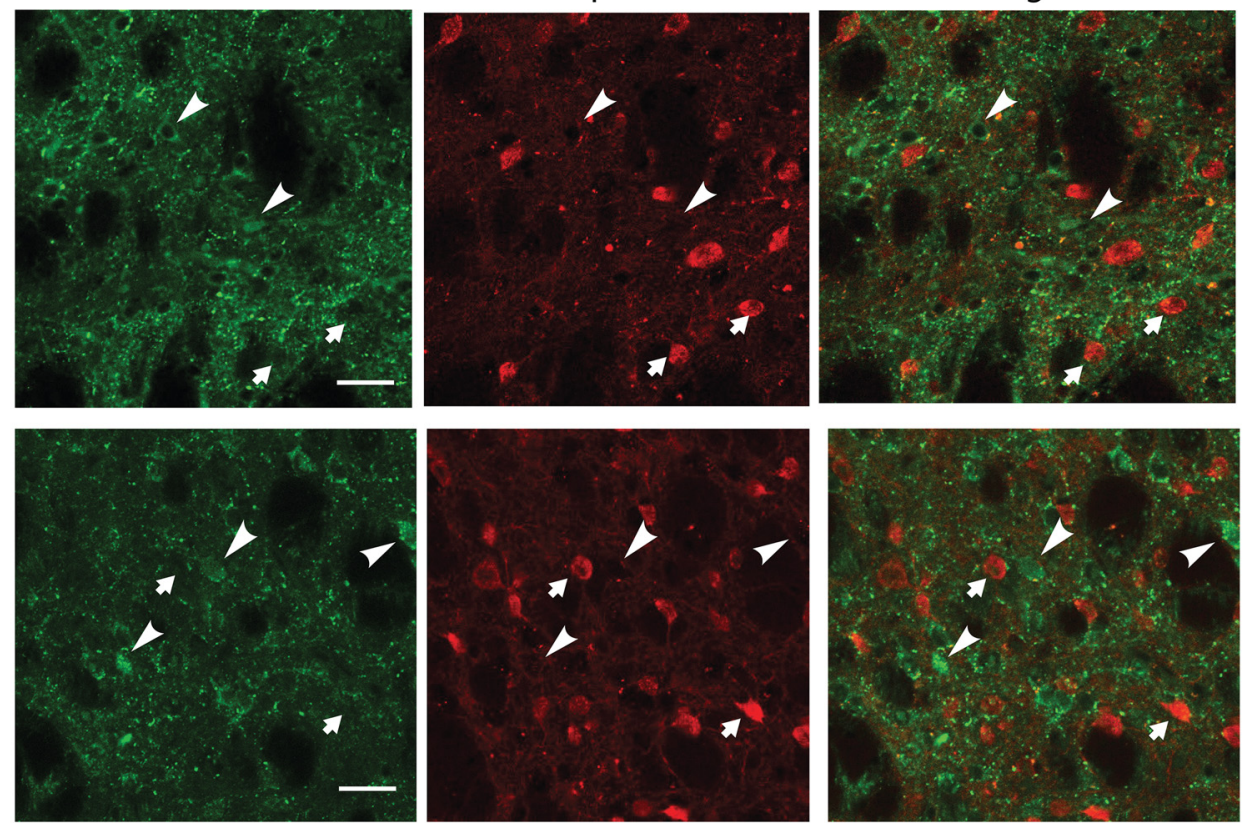

D

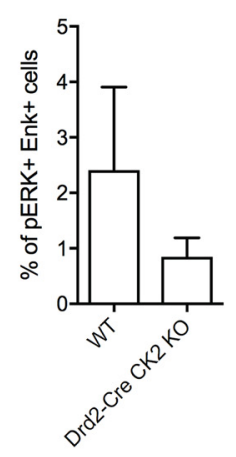

Figure 6. Characterization of anti-enkephalin antibody in the striatum. Tile scan of a coronal slice stained with the Enk antibody $(\boldsymbol{A})$. Immunohistochemical analysis of the dorsolateral striatum of coronal slices from WT mice that express GFP in direct projection neurons using Enk and GFP antibodies (B). Arrowheads indicate D1 cells that always lack Enk signal. Arrows indicate cells that can be identified as Enk-expressing cells. All of these cells lack GFP signal. Immunohistochemical analysis of the dorsolateral striatum of coronal slices from Drd2/Cre ${ }^{\mathrm{K} 0}$ and WT mice using Enk and pERK antibodies (C). Arrowheads indicate cells that express enkephalin; arrows show pERK-positive cells. Scale bar, $50 \mu \mathrm{m}$. Quantification of percentage pERK + cells that are also Enk + in Drd2/Cre ${ }^{K 0}$ and WT (D). Data are mean \pm SEM. $n=3(\boldsymbol{B}), n=6-8(\boldsymbol{D})$. 

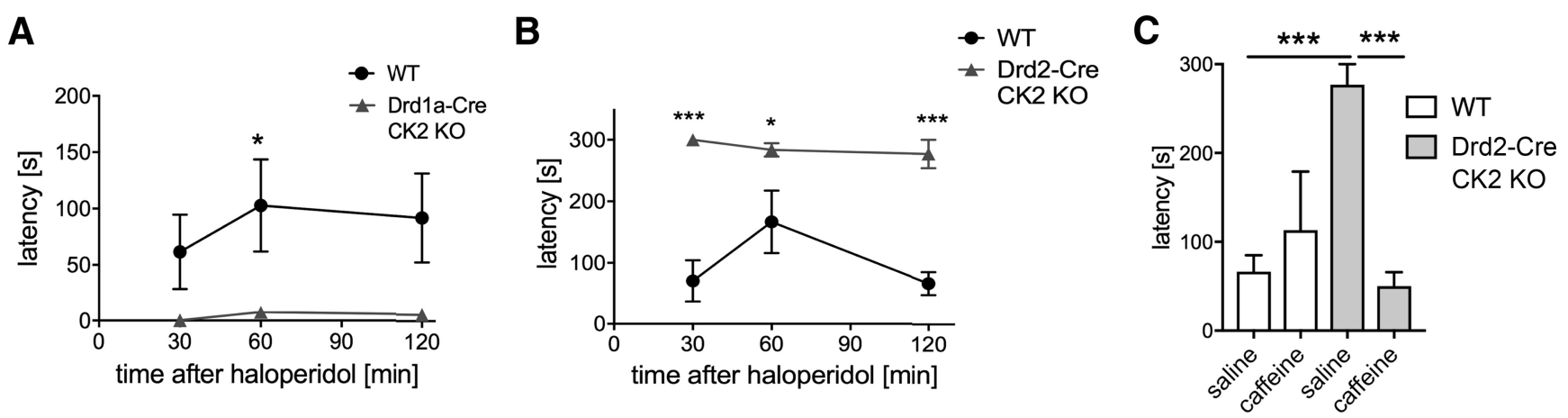

Figure 7. Haloperido-induced catalepsy is altered in opposing directions in Drd1a-Cre/CK2 ${ }^{\mathrm{K} 0}$ and Drd2-Cre/CK2 ${ }^{\mathrm{K} 0}$ mice. Latency to remove paws from bar was assessed at three time points $(30$, 60 , and $120 \mathrm{~min}$ after haloperidol injection) for Drd1a-Cre/CK2 ${ }^{\mathrm{KO}}(\boldsymbol{A})$ and for Drd2-Cre/CK2 ${ }^{\mathrm{KO}}(\boldsymbol{B})$. Caffeine $(0.5 \mathrm{mg} / \mathrm{kg})$ was injected at the same time than haloperidol and latency to remove paws from bar was measured at $120 \mathrm{~min}$ (C). Data are mean \pm SEM. ${ }^{*} p<0.05,{ }^{* * *} p<0.001 . n=10-11(\boldsymbol{A}), n=7-8(\boldsymbol{B}, \boldsymbol{C})$.

ing. To address this question, we coadministered caffeine with L-DOPA to unilaterally lesioned Drd2-Cre/CK2 ${ }^{\mathrm{KO}}$ mice and controls. We used caffeine at a dose of $2 \mathrm{mg} / \mathrm{kg}$, intraperitoneally because we had previously shown that at this dose locomotion was not affected. Caffeine antagonizes both $\mathrm{A}_{2 \mathrm{~A}}$ and $\mathrm{A}_{1}$ receptors with comparable affinity (Fredholm and Lindström, 1999; Fisone et al., 2004), and it has been shown that at the same dose of 2 $\mathrm{mg} / \mathrm{kg}$, administered intraperitoneally, the behavioral phenotype of enhanced wakefulness was completely abolished in conditional $\mathrm{A}_{2 \mathrm{~A}}$ receptor $\mathrm{KO}$ mice, indicating that at this dose the $\mathrm{A}_{2 \mathrm{~A}}$ receptor must be sufficiently affected (Lazarus et al., 2011). Unexpectedly, caffeine with L-DOPA $(20 \mathrm{mg} / \mathrm{kg})$ enhanced the ALO score of the WT mice while it did not significantly affect the score of Drd2-Cre/CK2 ${ }^{\mathrm{KO}}$ mice (Fig. $8 A$ ). Statistically, there was an effect of treatment $\left(F_{(1,36)}=7.109, p=0.011\right)$ and genotype $\left(F_{(1,36)}=10.32, p=0.028\right)$ and but no interaction genotype $\times$ treatment $\left(F_{(1,36)}=0.1953, p=0.661\right)$. Locomotor AIMs scores were not significantly altered in the presence of caffeine in either genotype (Fig. $8 B$ ). Although there was a statistically significant effect of genotype $\left(F_{(1,36)}=7.981, p=0.008\right)$, there was no interaction genotype $\times$ treatment $\left(F_{(1,36)}=0.055, p=0.817\right)$. Similarly, total AIMs scores were not significantly altered in the presence of caffeine in either genotype (Fig. $8 C, D$ ). Statistically, there was no interaction genotype $\times$ treatment $\left(F_{(1,32)}=0.084\right.$, $p=0.775)$ but an effect of genotype $\left(F_{(1,32)}=8.689, p=0.006\right)$. It was shown that low doses of caffeine exerted anti-dyskinetic effects, whereas higher doses have a motor stimulant action that may exacerbate LID (Xiao et al., 2011). Previous rodent studies have reported that the anti-dyskinetic effects of $A_{2 A} R$ antagonists were achieved when AIMs were induced with low doses of L-DOPA (Pinna et al., 2001; Xiao et al., 2011). We thus tested the effects of caffeine on AIMs induced by a low dose of L-DOPA (2 $\mathrm{mg} / \mathrm{kg}$ ). Due to the low dose of L-DOPA used, treatment was performed over a longer time period and AIMs development tested at three time points $(5,12,17 \mathrm{~d})$. On all days tested, caffeine had a particularly strong effect on ALO AIMs in the Drd2Cre/ $\mathrm{CK} 2{ }^{\mathrm{KO}}$, abolishing the difference between the genotypes (Fig. $8 E)$. Statistically, there was a genotype $\times$ treatment interaction $\left(F_{(1,18)}=4.99, p=0.038\right)$. Neither for WT nor for the Drd2Cre/ $\mathrm{CK} 2{ }^{\mathrm{KO}}$ did caffeine affect locomotor scores significantly (Fig. $8 F$ ). There was an effect of genotype $\left(F_{(1,18)}=8.454, p=0.009\right)$ but not treatment $\left(F_{(1,18)}=1.422, p=0.249\right)$, and no interaction genotype $\times$ treatment $\left(F_{(1,18)}=1.751, p=0.202\right)$. The total AIMs score was reduced in Drd2-Cre/CK2 ${ }^{\mathrm{KO}}$ but not WT mice (Fig. 8G,H). Statistically, there was an interaction genotype $\times$ treatment $\left(F_{(1,18)}=\right.$
4.76, $p=0.043)$ as well as a treatment effect $\left(F_{(1,18)}=7.03, p=\right.$ $0.016)$ and genotype effect $\left(F_{(1,18)}=7.221, p=0.015\right)$. We found that the effect of caffeine was preserved up to $17 \mathrm{~d}$ (Fig. 8I) and was already present after $5 \mathrm{~d}$ (data not shown).

Because the elevated AIMs in the Drd2-Cre/CK2 ${ }^{\mathrm{KO}}$ can be normalized by caffeine, we hypothesized that striatal pERK levels may be reduced, too. This was indeed the case (Fig. 9A). Upon treatment with $2 \mathrm{mg} / \mathrm{kg}$ L-DOPA, Drd2-Cre/CK2 ${ }^{\mathrm{KO}}$ mice receiving vehicle cotreatment showed a strong upregulation of pERK, which was completely prevented by caffeine cotreatment (Fig. $9 B)$. Statistically, there was a genotype $\times$ treatment interaction $\left(F_{(1,19)}=4.929, p=0.038\right)$.

Caffeine did not affect pERK expression in ChAT-positive cells (Fig. $9 C$ ) and there was no significant interaction genotype $\times$ treatment $\left(F_{(1,19)}=0.240, p=0.630\right)$.

\section{Effect of CK2 inhibitor CX4945 on LID}

To determine whether acute inhibition of CK2 affects LID in unilaterally lesioned WT mice, we chose to use CX4945, the only known CK2 inhibitor that is bioavailable and has been shown to have an effect on glioblastoma growth in vivo (Zheng et al., 2013). We performed several dose course experiments that lead us to determine that only at very high doses (75 or $150 \mathrm{mg} / \mathrm{kg}$, i.p.), there is a reduction in CK2 phosphorylation site on Akt (S129), accompanied by a dephosphorylation of pS473Akt (Fig. 10A). However, these doses lead to rigidity in the animals for $\sim 15 \mathrm{~min}$ post-injection, suggesting that the use of this inhibitor is not ideal for behavioral experiments. We have injected CX4945 (100 $\mathrm{mg} / \mathrm{kg}$ ) $15 \mathrm{~min}$ before L-DOPA injection to 6-OHDA-lesioned medial forebrain bundle lesioned, dyskinetic mice. No significant difference in the LID scores was observed (Fig. $10 \mathrm{~B}, C$ ), and no interaction of time $\times$ treatment could be detected $\left(F_{(5,84)}=\right.$ $0.195, p=0.984$ for ALO and $F_{(5,84)}=0.140, p=0.982$ for LOC AIMs scores). Future experiments will be performed to unambiguously answer the relation of acute CK2 inhibition and LID, to ensure that sufficient CK2 inhibition occurs and that phosphorylation site/s relevant for the LID phenotype is/are dephosphorylated.

\section{G $\alpha_{\text {olf }}$ expression}

We have previously shown that CK2 interacts with the G-protein $\mathrm{G} \alpha_{\text {olf }}$ (Rebholz et al., 2009), the major G-protein in the striatum mediating cAMP/PKA signaling in response to D1 receptor stimulation. Moreover, $\mathrm{G} \alpha_{\text {olf }}$ expression can be modulated by DA depletion and L-DOPA treatment (Corvol et al., 2007). We therefore tested whether striatal levels of $\mathrm{G} \alpha_{\text {olf }}$ were altered in the 
A

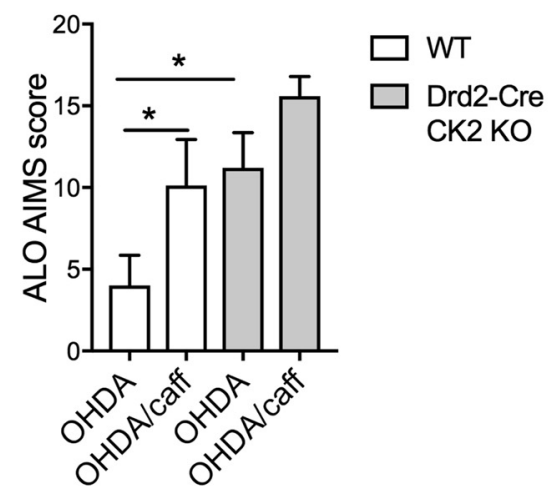

D

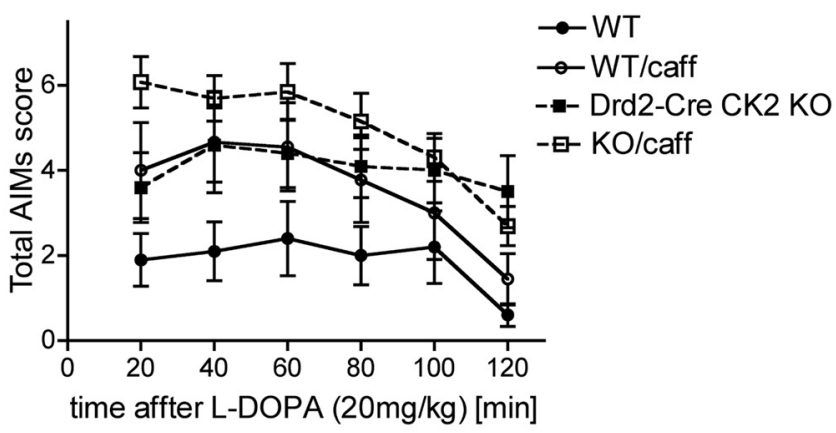

B

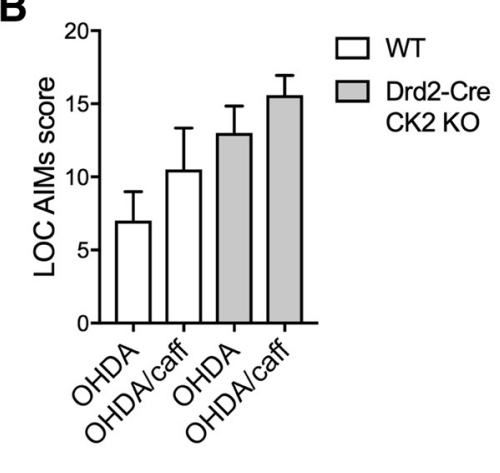

C

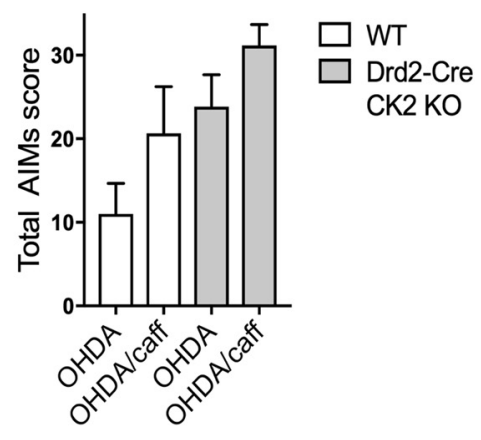

E

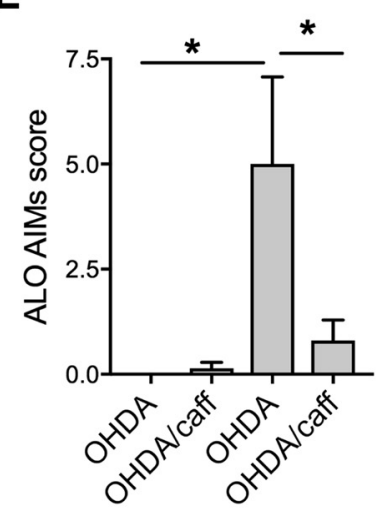

$\mathbf{F}$

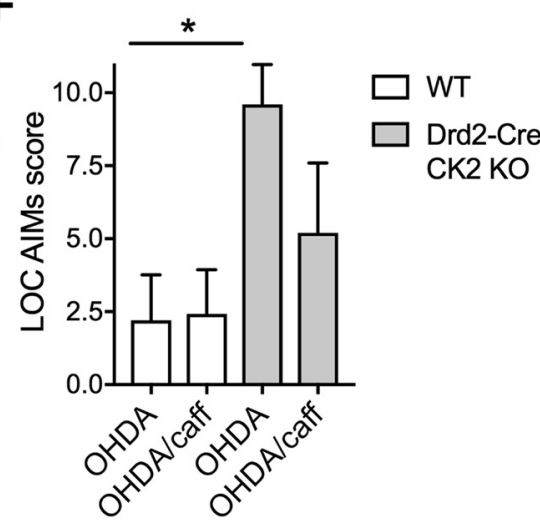

G

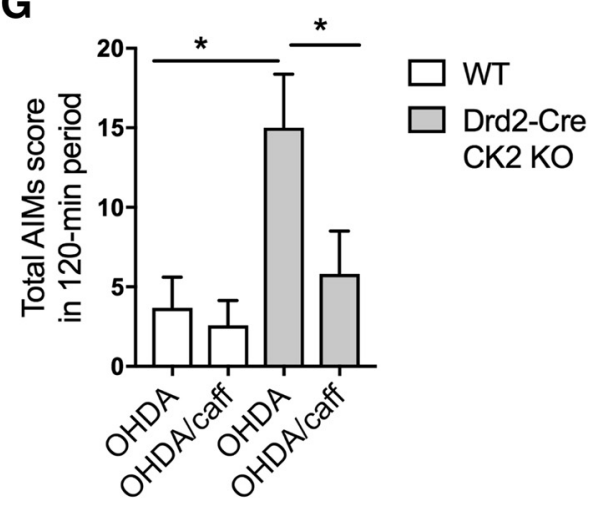

H

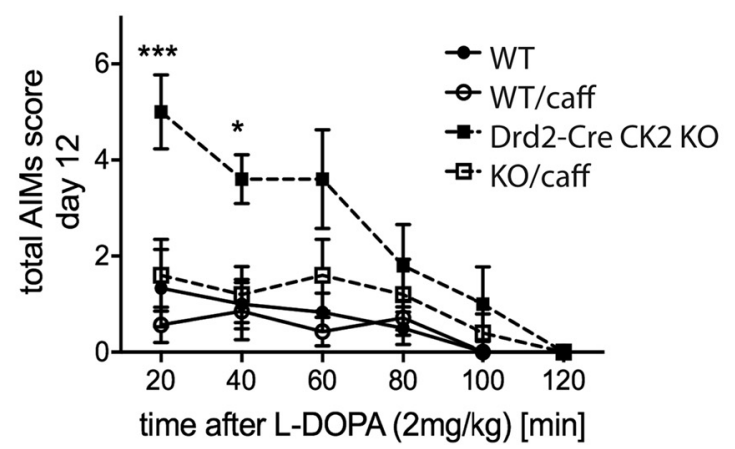

I

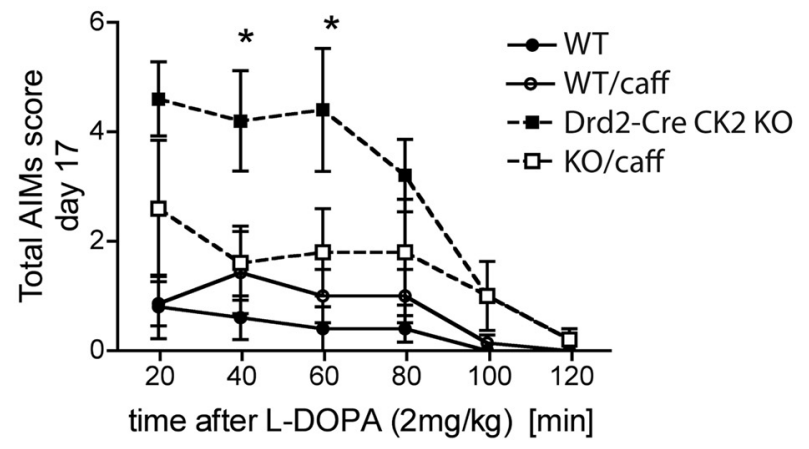

Figure 8. LID of Drd2-Cre/CK2 ${ }^{\mathrm{K} 0}$ mice in the presence of caffeine. $6-0 \mathrm{HDA}$ lesioned Drd2-Cre $/ \mathrm{CK} 2{ }^{\mathrm{K} 0}$ mice were treated with L-DOPA/benserazide (20 mg/kg/12.5 mg/kg, i.p.) and caffeine $(2 \mathrm{mg} / \mathrm{kg}$, i.p.) for $7 \mathrm{~d}$. ALO score $(\boldsymbol{A})$, LOC score $(\boldsymbol{B})$, and total AIMs scores were determined and plotted as summarized score $(\boldsymbol{C})$ or at 20 min time points over $2 \mathrm{~h}$ after L-DOPA injection (D). 6-0HDA lesioned Drd2-Cre/CK2 ${ }^{\mathrm{K} 0}$ or WT mice were treated with low-dose L-DOPA/benserazide/caffeine ( $2 \mathrm{mg} / \mathrm{kg} / 12.5 \mathrm{mg} / \mathrm{kg} / 2 \mathrm{mg} / \mathrm{kg}$, i.p.) for $17 \mathrm{~d}$ and tested at 5,12 , and 17 d. ALO score (E), LOC score $(\boldsymbol{F})$, and total summarized AIMs scores $(\boldsymbol{G})$ or total AIMs scores plotted over time $(\boldsymbol{H})$ after $12 \mathrm{~d}$ are shown. $17 \mathrm{~d}$ of treatment do no significantly alter the total AIMs scores $(\boldsymbol{I})$, Data are mean \pm SEM. ${ }^{*} p<0.05,{ }^{* * *} p<0.001 . n=8-12(\boldsymbol{A}-\boldsymbol{D}) . n=5-7(\boldsymbol{E}-\boldsymbol{I})$. caff, Caffeine. 
A
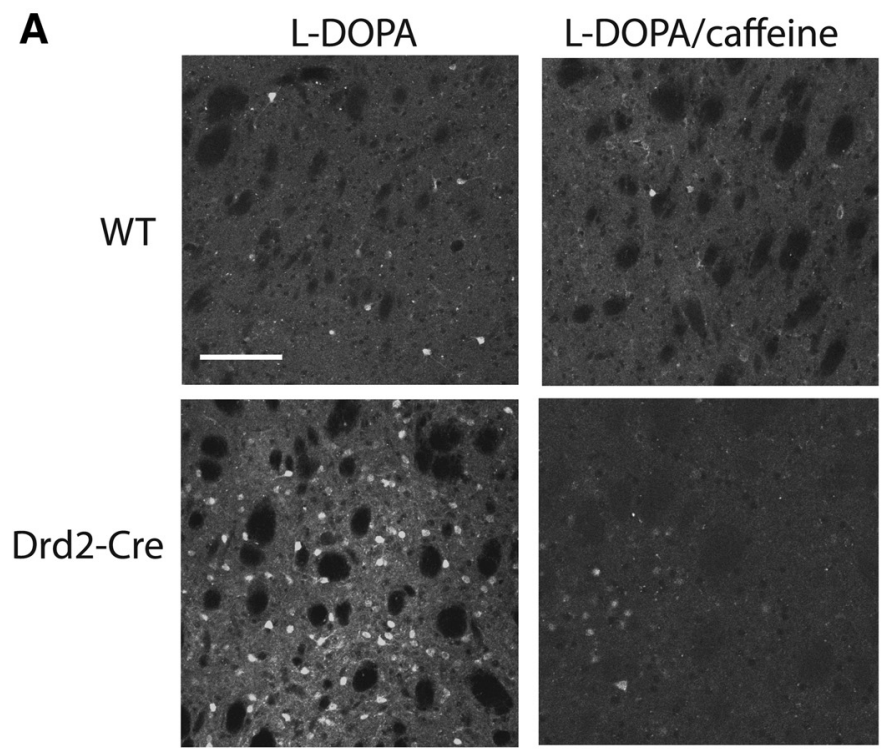

B

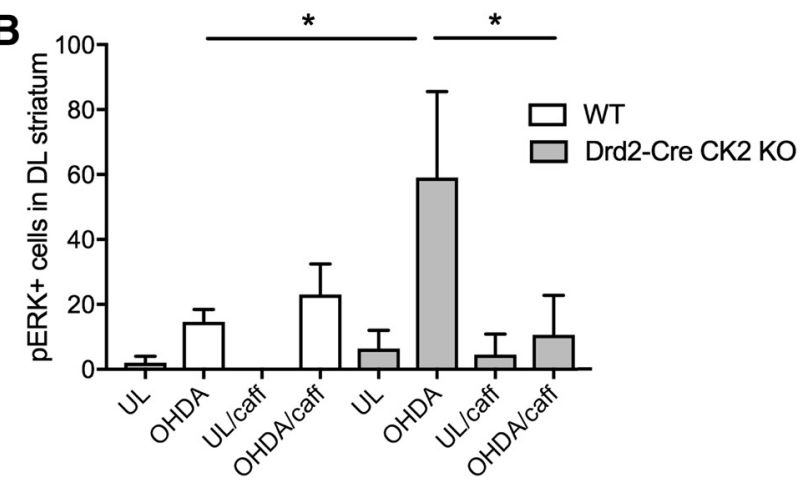

C

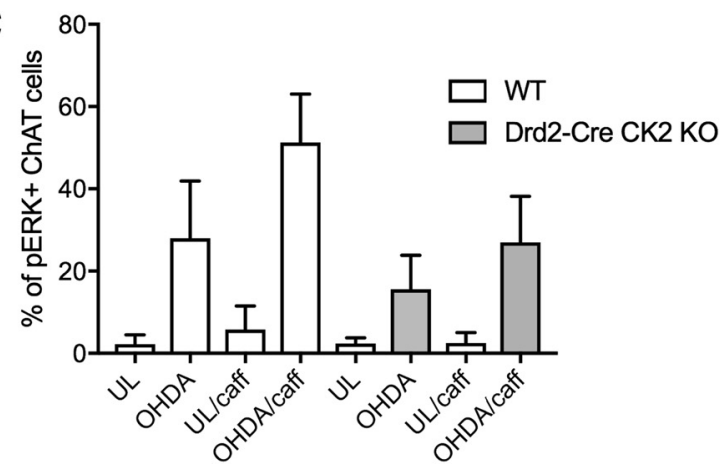

Figure 9. ERK1/2 phosphorylation is normalized in the presence of caffeine in Drd2-Cre/CK2 ${ }^{\mathrm{K} 0}$ mice. IHC analysis of dorsolateral striatum of coronal slices from WT and Drd2-Cre/CK2 ${ }^{\mathrm{K} 0}$ mice after L-DOPA treatment [L-DOPA/benserazide $2 \mathrm{mg} / \mathrm{kg} / 12.5 \mathrm{mg} / \mathrm{kg}$, with or without caffeine ( $2 \mathrm{mg} / \mathrm{kg}$, i.p.); $\boldsymbol{A}]$. Quantification of immunofluorescence of pERK1/2-positive cells (B). Quantification of immunofluorescence of cells that are positive for pERK1/2 and ChAT normalized by the total number of ChAT-positive neurons (C). Scale bar, $100 \mu \mathrm{m}$. Data are mean \pm SEM. ${ }^{*} p<0.05 . n=6-7$ per group. caff, Caffeine.

A

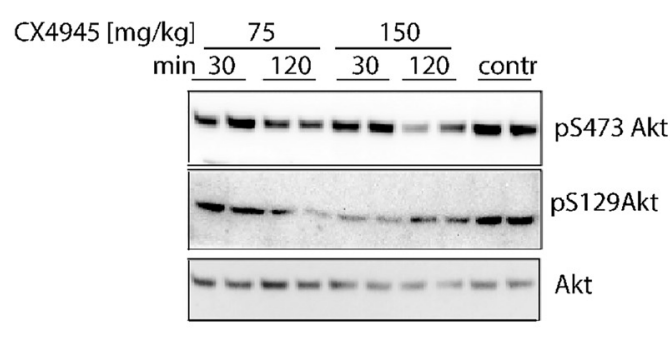

B

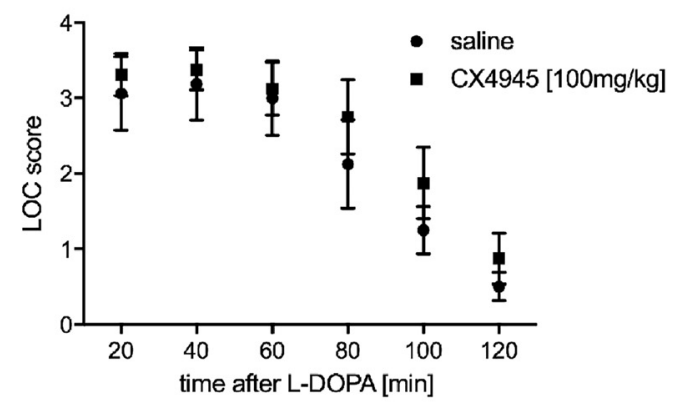

C

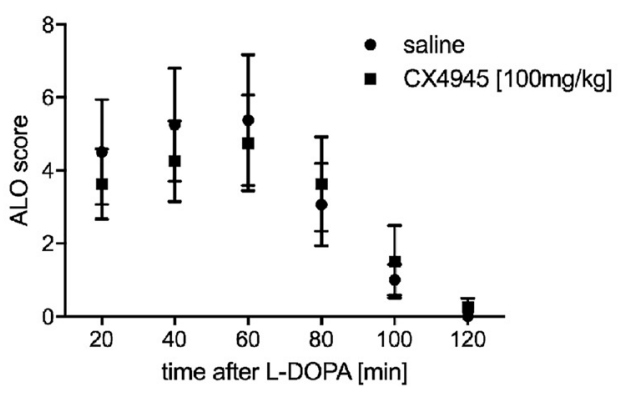

Figure 10. AIMs in presence of CK2 inhibitor CX4945. Western blot analysis of lysates derived from mice acutely treated with CX4945 by interaperitoneal injection (A). Mice were lesioned with 6-OHDA targeted to the MFB and treated for $10 \mathrm{~d}$ with L-DOPA $3 \mathrm{mg} / \mathrm{kg} /$ benserazide (10 mg/kg). Mice were pre-injected with CX4945 (100 mg/kg, i.p.) $15 \mathrm{~min}$ before L-DOPA administration. LOC and ALO AIMs scores were assessed $(\boldsymbol{B}, \boldsymbol{C})$. Data are mean \pm SEM. $n=8$ per group.

conditional CK2 KO mice following 6-OHDA lesion and L-DOPA treatment. In Drd1a-Cre/CK2 ${ }^{\mathrm{KO}}$ mice treated with L-DOPA, $\mathrm{G} \alpha_{\text {olf }}$ levels were reduced in the DA-depleted hemisphere but unaltered in the contralateral side (Fig. $11 A, B$ ), $p=0.039$ for $\mathrm{G}_{\text {olf }}$ unle- sioned versus lesioned side of the Drd1a-Cre/CK2 ${ }^{\mathrm{KO}}$ and $p=$ 0.983 for the WT. In contrast, in the Drd2-Cre/CK2 ${ }^{\mathrm{KO}}$ mice, $\mathrm{G} \alpha_{\text {olf }}$ levels were not changed under any of the experimental conditions examined (Fig. 11C,D). 
A

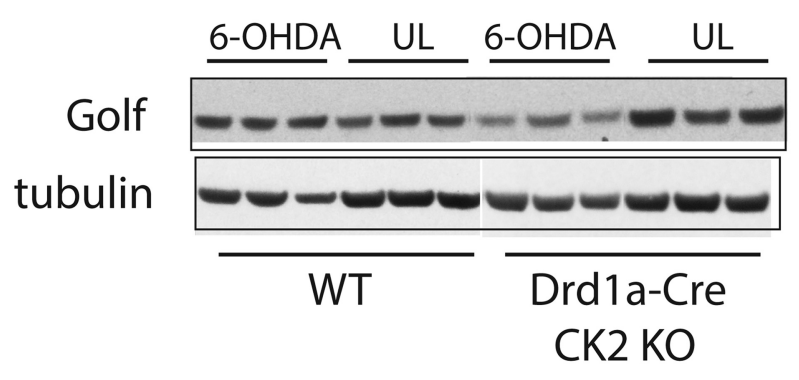

B

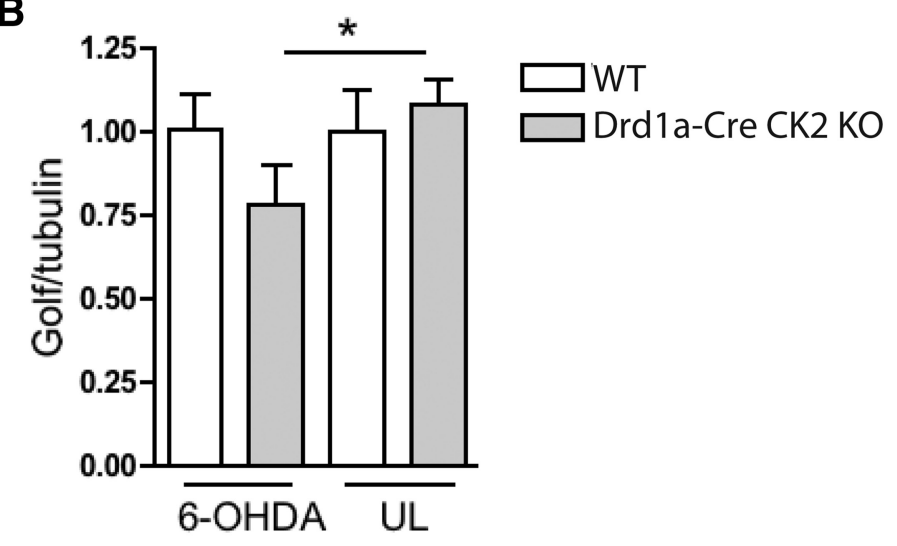

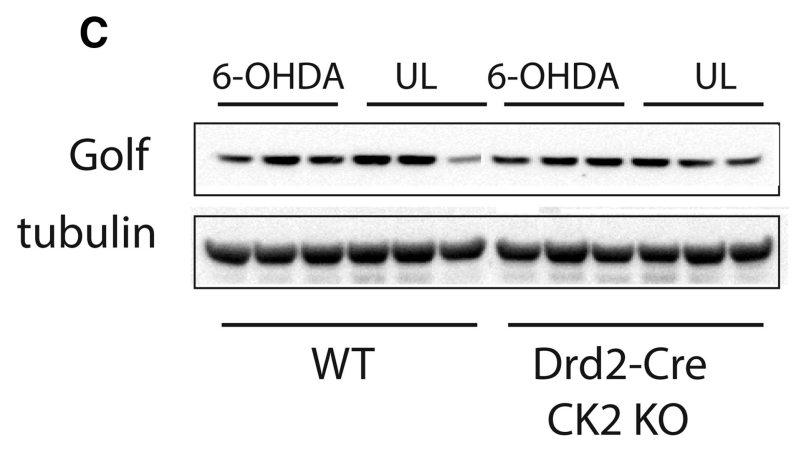

D

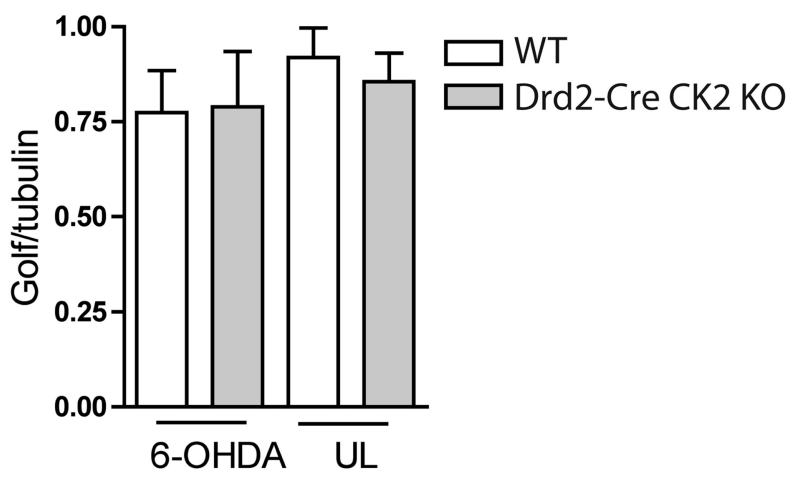

Figure 11. $G_{\text {off }}$ levels are reduced in the Drd1a-Cre/CK2 ${ }^{\mathrm{K} 0}$. Total striatal protein lysates $(40 \mu \mathrm{g})$ from lesioned and unlesioned hemispheres of Drd1a-Cre/CK2 ${ }^{\mathrm{K} 0}$ and WT mice were separated by SDS/PAGE. Immunoblotting analysis with anti- $\mathrm{G}_{\text {olf }}(\boldsymbol{A})$ was performed and quantified $(\boldsymbol{B})$. Lysates from Drd2-Cre/CK2 ${ }^{\mathrm{KO}}$ and WT mice were similarly analyzed $(\boldsymbol{C}, \boldsymbol{D})$. Quantification derived from ImageJ density measurements is shown. Animals were treated with L-DOPA/Benserazide for $7 \mathrm{~d}(\boldsymbol{D})$. Data are mean \pm SEM. ${ }^{*} p<0.05 . n=10-11$ (B), $n=5-7$ (D).

\section{Discussion}

Our study investigates the role of CK2 in the development of LID in the mouse 6-OHDA lesion model of PD. Knock-out of CK $2 \alpha$ in projection neurons of the direct pathway reduced dyskinesia, whereas knock-out of $\mathrm{CK} 2 \alpha$ in neurons forming the indirect pathway enhanced LID. These results reveal that CK2 regulates signaling events critical to LID in each of the two main populations of striatal neurons.

Dyskinesia and striatal signaling in Drd1a-Cre/CK $2{ }^{\mathrm{KO}}$ mice The reduced LID severity in Drdla-Cre/CK2 ${ }^{\mathrm{KO}}$ was at first surprising because we had previously shown that reduction or ablation of CK2 activity/expression enhances D1 receptor signaling (Rebholz et al., 2009, 2013). A preliminary indication for a reduced sensitivity to L-DOPA in these conditional KO mice came from the assessment of contralateral paw use in the cylinder test. Whereas at low doses of L-DOPA ( 2 and $5 \mathrm{mg} / \mathrm{kg}$ ) no difference in anti-akinetic response between Drd1a-Cre/CK2 ${ }^{\mathrm{KO}}$ and WT was detected, at $10 \mathrm{mg} / \mathrm{kg}$ the $\mathrm{KO}$ mice responded to a lesser extent than WT littermates.

Phosphorylation of ERK in D1-MSNs has been linked to LID development (Gerfen et al., 2002; Santini et al., 2007). Other markers indicative of direct pathway hyperactivity in LID involve an elevated phosphorylation of members of the cAMP/PKA/DARPP-32 cascade, and the expression of c-Fos, FosB, and $\Delta$ FosB (Asin et al., 1995; Andersson et al., 1999; Cenci et al., 1999; Lopez et al., 2001). Inhibition of PKA (Lebel et al., 2010) and inactivation or knock- out of DARPP-32 (Santini et al., 2007; Bateup et al., 2010) have shown to reduce dyskinetic behavior in rodent models. However, others have shown that although pERK appears to be absolutely required for AIM development, pPKA substrate phosphorylation (including the PKA-mediated phosphorylation GluR1) can be reduced without affecting LID (Alcacer et al., 2012). Our data show that following L-DOPA treatment, levels of ERK phosphorylation in the DA-denervated striatum were reduced in the Drdla-Cre/ $\mathrm{CK} 2^{\mathrm{KO}}$, in concordance with the reduced LID phenotype, whereas pPKA substrate phosphorylation and c-fos levels were not affected.

Recent studies have revealed an involvement of cholinergic interneurons in LIDs. Prolonged L-DOPA treatment leads to diminished pERK expression in D1 striatal projection neurons and increased expression in ChAT interneurons (Ding et al., 2011). Inhibition or ablation of ChAT interneurons prevents the development of LID (Ding et al., 2011; Won et al., 2014). In Drd1a-Cre/ $\mathrm{CK} 2{ }^{\mathrm{KO}}$ mice, ERK signaling in the ChAT neurons was also reduced. We assessed whether the Drd1a-Cre driver ablates CK $2 \alpha$ expression also in ChAT neurons, but this was not the case. In the Drd2-Cre/ $\mathrm{CK} 2{ }^{\mathrm{KO}}$ mice, however, CK2 was ablated also in the ChATimmunoreactive neurons. Despite their lacking CK2, these neurons did not exhibit changes in L-DOPA-induced ERK phosphorylation in the Drd2-Cre/CK2 ${ }^{\mathrm{KO}}$. Together, these data suggest that the changes in dyskinesia severity and ERK signaling were not primarily driven by cholinergic interneurons. When these neurons appeared 
affected, the effect possibly depended on network-level changes primarily driven by the spiny projection neurons.

$\mathrm{G} \alpha_{\text {olf, }}$ is a rate-limiting component of the dopamine D1 signaling cascade (Corvol et al., 2004, 2007). Levels of $\mathrm{G} \alpha_{\text {olf }}$ increase in DA-denervated striatum of PD patients and rodents (Hervé et al., 1993; Marcotte et al., 1994; Penit-Soria et al., 1997; RangelBarajas et al., 2011) and are normalized after L-DOPA (Corvol et al., 2004). We have previously shown that CK2 binds to $\mathrm{G} \alpha_{\text {olf }}$ (Rebholz et al., 2009). We therefore examined $\mathrm{G} \alpha_{\text {olf }}$ striatal levels, and found them reduced in the 6-OHDA-lesioned side in Drdla$\mathrm{Cre} / \mathrm{CK} 2{ }^{\mathrm{KO}}$ mice after chronic L-DOPA. This finding appears to parallel the reduced severity of LID in the same animals. G $\alpha_{\text {olf }}$ haploinsufficiency has been found not to affect dyskinesia development, or pERK upregulation, in 6-OHDA-lesioned mice treated with L-DOPA (Alcacer et al., 2012). This may suggest that the reduction in $\mathrm{G} \alpha_{\text {olf }}$ levels observed in Drd1a-Cre/CK2 ${ }^{\mathrm{KO}}$ mice does not play a causal role in their lowered susceptibility to LID. In keeping with this interpretation, Drd1a-Cre/CK2 ${ }^{\mathrm{KO}}$ mice treated with L-DOPA did not show altered levels of PKA phosphosubstrates, which indirectly indicate that the canonical signaling cascade triggered through $\mathrm{G} \alpha_{\text {olf }}$ is intact.

On the other hand, our case is different since the changes in $\mathrm{G} \alpha_{\text {olf }}$ expression either stem from 6-OHDA and/or L-DOPA and are thus a response to perturbation of the system whereas in the heterozygous mouse the $\mathrm{G} \alpha_{\text {olf }}$ levels are already present prenatally. Furthermore, the conditional KO mice are devoid of CK2 activity in either D1 or D2 projection neurons but not in both cell types. Interestingly, it was recently published that upon chronic L-DOPA treatment the negative regulator of $\mathrm{G} \alpha_{\mathrm{s}} / \mathrm{G} \alpha_{\mathrm{olf}}$, RGS6, is upregulated, indicating that compensatory mechanisms are elicited to dampen $\mathrm{G} \alpha_{s} / \mathrm{G} \alpha_{\text {olf }}$ signaling (Heiman et al., 2014). Thus, the fact that CK2 depletion reduces the G-protein in the lesioned hemisphere in the Drdla-Cre/CK2 ${ }^{\mathrm{KO}}$ may still be relevant for our LID phenotype.

CK2 was shown to phosphorylate ERK within its nuclear translocation signal (NLS; Plotnikov et al., 2011). This site, S246, becomes phosphorylated after ERK is activated on T202/Y204, which are the sites examined in the presented work. Therefore, lack phosphorylation within the NLS of ERK due to CK2 KO may negatively affect longer-term adaptive changes to L-DOPA because it is expected that ERK may not be able to translocate sufficiently to the nucleus to promote transcriptional events, thereby possibly affecting the LID phenotype of both CK2 knock-out lines.

\section{Dyskinesia and striatal signaling in Drd2-Cre/CK2 ${ }^{\mathrm{KO}}$ mice}

Genetic ablation of CK2 in D2 striatal neurons resulted in increased LID severity and enhanced striatal activation of ERK signaling in D1 striatal neurons indicating a non-cell-autonomous regulation of this phosphorylation event. These effects may be mediated, at least in part, via $\mathrm{A}_{2 \mathrm{~A}}$ receptors, which are highly expressed in indirect pathway striatal neurons.

There is growing evidence for $\mathrm{A}_{2 \mathrm{~A}}$ receptors as a promising drug target for the treatment of PD. Human imaging studies have revealed a link between LID and increased $\mathrm{A}_{2 \mathrm{~A}}$ signaling (Ramlackhansingh et al., 2011). $\mathrm{A}_{2 \mathrm{~A}} \mathrm{R}$ antagonists exert potent antiakinetic effects in animal models (Chen et al., 2001; Pinna et al., 2001; Bibbiani et al., 2003; Joghataie et al., 2004; Matsuya et al., 2007) and are currently being evaluated in clinical trials (Prediger, 2010; Postuma et al., 2012). The specific $A_{2 A} R$ antagonist, KW-6002, alleviates parkinsonian symptoms, including dyskinesia, in MPTP lesioned monkeys treated with low-dose L-DOPA (Kanda et al., 1998; Grondin et al., 1999). Our results implicate $\mathrm{A}_{2 \mathrm{~A}}$ signaling in the increased LID susceptibility of Drd2a-Cre/ $\mathrm{CK} 2{ }^{\mathrm{KO}}$ mice. As others, we do not detect a reduction of LID with adenosine receptor antagonist caffeine when animals are treated with high-dose L-DOPA. However, the high AIM scores induced in Drd2a-Cre/CK2 ${ }^{\mathrm{KO}}$ mice by a low dose of L-DOPA were completely eliminated by caffeine.

$A_{2 A}$ receptors exert a strong excitatory influence on indirect pathway neurons: $\mathrm{A}_{2 \mathrm{~A}} \mathrm{R}$ activation leads to an elevation of cAMP and thus antagonizes $\mathrm{D} 2$ signaling. $\mathrm{D} 2 \mathrm{R}$ and $\mathrm{A}_{2 \mathrm{~A}} \mathrm{R}$ signaling are negatively coupled and by forming heterodimers with $\mathrm{D} 2$ receptors, $A_{2 A}$ Rs affect $D 2$ receptor affinity for dopamine agonists and G-protein coupling (Díaz-Cabiale et al., 2001; Canals et al., 2003; Fuxe et al., 2014). Furthermore, it was postulated that LIDs may be caused by altered expression of $\mathrm{A}_{2 \mathrm{~A}} / \mathrm{D} 2$ heteromers versus $\mathrm{A}_{2 \mathrm{~A}}$ homomers at the cell membrane (Antonelli et al., 2006). Such a scenario can be imagined to be the case in Drd2-Cre/CK2 ${ }^{\mathrm{KO}}$ mice where the level of $A_{2 A} R$ is elevated (Rebholz et al., 2013). Enhanced $\mathrm{A}_{2 \mathrm{~A}}$ signaling in the Drd2-Cre/CK2 ${ }^{\mathrm{KO}}$ mice may correlate with reduced D2R signaling, which may result in a proportionately larger effect of L-DOPA on the direct pathway. In turn, an imbalance between pathways (with higher activity of the direct one) is likely to favor LID. Furthermore, activation of the $A_{2 A} R$ within $\mathrm{A}_{2 \mathrm{~A}} \mathrm{R} / \mathrm{D} 2 \mathrm{R}$ heterodimers will lead to a biased modulation of D2R signaling, decreasing $\mathrm{G}_{\mathrm{i} / \mathrm{o}}$ signaling and increasing D2Rmediated $\beta$-arrestin2/Akt/PP2A signaling (Fuxe et al., 2014). The effect of this signaling cascade on LID has not been well studied. It is however known that chronic L-DOPA elevates Akt phosphorylation and activity in 6-OHDA lesioned rats (Bychkov et al., 2007). Thus, it is tempting to speculate that upregulated $\mathrm{A}_{2 \mathrm{~A}} \mathrm{R}$ signaling in Drd2-Cre/CK2 ${ }^{\mathrm{KO}}$ animals may correspond to high Akt/PP2A activity, which in turn leads to the higher severity of LID.

Finally, it is expected that, in Drd2-Cre/CK2 ${ }^{\mathrm{KO}}$ mice, CK2 $\alpha$ is absent from DA neurons and thus there is the possibility that this difference in CK2 $\alpha$ expression may also contribute to the phenotype of the KO mice. The extent of the 6-OHDA lesion is similar in WT and Drd2-Cre KO, but since not all of the midbrain neurons are expected to be destroyed by 6-OHDA, we cannot exclude that altered activity of these dopaminergic neurons may play a role in the phenotype.

\section{Concluding remarks}

Our data indicate that altered $\mathrm{D} 1$ receptor signaling in direct pathway neurons and enhanced $\mathrm{A}_{2 \mathrm{~A}} \mathrm{R}$ signaling in indirect pathway neurons underlie the opposite changes in susceptibility to LID seen in the two CK2 knock-out lines. The behavioral results of reduced or enhanced dyskinesia severity are consistent with the accompanying changes in ERK activation in the DA-denervated striatum. One important aspect in the development of LID are DA fluctuations induced by standard L-DOPA therapy, which leads to dramatic on-off changes in the activity of DA receptors (Olanow and Obeso, 2000). Against this background, reduced dynamics of DA receptor endocytosis may have important effects (Ahmed et al., 2010). In previous studies, we have shown that ablation of CK2 prevents or slows the endocytosis of D1 receptors, possibly by its interaction with $G \alpha_{\text {s/olf }}$ (Rebholz et al., 2009). Such an effect may counteract fast fluctuations of dopaminergic signaling and thus underlie the behavioral phenotype of reduced LID of the Drd1a-Cre/CK2 ${ }^{\mathrm{KO}}$ mice.

Together, our results reveal a previously unappreciated role of CK2 in the striatal pathophysiology of motor complications in response to L-DOPA therapy. Moreover, the bidirectional modulation of dyskinesia seen upon ablation of CK2 in either class of striatal projection neurons reveals that both direct and indirect pathways contribute to LID. 


\section{References}

Ahmed MR, Berthet A, Bychkov E, Porras G, Li Q, Bioulac BH, Carl YT, Bloch B, Kook S, Aubert I, Dovero S, Doudnikoff E, Gurevich VV, Gurevich EV, Bezard E (2010) Lentiviral overexpression of GRK6 alleviates L-dopainduced dyskinesia in experimental Parkinson's disease. Sci Transl Med 2:28ra28. CrossRef Medline

Alcacer C, Santini E, Valjent E, Gaven F, Girault JA, Hervé D (2012) G $\alpha_{\text {olf }}$ mutation allows parsing the role of cAMP-dependent and extracellular signal-regulated kinase-dependent signaling in L-3,4-dihydroxyphenylalanine-induced dyskinesia. J Neurosci 32:5900-5910. CrossRef Medline

Andersson M, Hilbertson A, Cenci MA (1999) Striatal fosB expression is causally linked with 1-DOPA-induced abnormal involuntary movements and the associated upregulation of striatal prodynorphin mRNA in a rat model of Parkinson's disease. Neurobiol Dis 6:461-474. CrossRef Medline

Antonelli T, Fuxe K, Agnati L, Mazzoni E, Tanganelli S, Tomasini MC, Ferraro L (2006) Experimental studies and theoretical aspects on A2A/D2 receptor interactions in a model of Parkinson's disease. Relevance for L-dopa induced dyskinesias. J Neurol Sci 248:16-22. CrossRef Medline

Asin KE, Bednarz L, Nikkel A, Perner R (1995) Rotation and striatal c-fos expression after repeated, daily treatment with selective dopamine receptor agonists and levodopa. J Pharmacol Exp Ther 273:1483-1490. Medline

Aubry JM, Schulz MF, Pagliusi S, Schulz P, Kiss JZ (1993) Coexpression of dopamine D2 and substance $\mathrm{P}$ (neurokinin-1) receptor messenger RNAs by a subpopulation of cholinergic neurons in the rat striatum. Neuroscience 53:417-424. CrossRef Medline

Bateup HS, Santini E, Shen W, Birnbaum S, Valjent E, Surmeier DJ, Fisone G, Nestler EJ, Greengard P (2010) Distinct subclasses of medium spiny neurons differentially regulate striatal motor behaviors. Proc Natl Acad Sci U S A 107:14845-14850. CrossRef Medline

Bezard E, Brotchie JM, Gross CE (2001) Pathophysiology of levodopainduced dyskinesia: potential for new therapies. Nat Rev Neurosci 2:577588. CrossRef Medline

Bibbiani F, Oh JD, Petzer JP, Castagnoli N Jr, Chen JF, Schwarzschild MA, Chase TN (2003) A2A antagonist prevents dopamine agonist-induced motor complications in animal models of Parkinson's disease. Exp Neurol 184:285-294. CrossRef Medline

Boix J, Padel T, Paul G (2015) A partial lesion model of Parkinson's disease in mice: characterization of a 6-OHDA-induced medial forebrain bundle lesion. Behav Brain Res 284:196-206. CrossRef Medline

Boulay D, Depoortere R, Oblin A, Sanger DJ, Schoemaker H, Perrault G (2000) Haloperidol-induced catalepsy is absent in dopamine $\mathrm{D}_{2}$, but maintained in dopamine $\mathrm{D}_{3}$ receptor knock-out mice. Eur J Pharmacol 391:63-73. CrossRef Medline

Buchou T, Vernet M, Blond O, Jensen HH, Pointu H, Olsen BB, Cochet C, Issinger OG, Boldyreff B (2003) Disruption of the regulatory beta subunit of protein kinase CK2 in mice leads to a cell-autonomous defect and early embryonic lethality. Mol Cell Biol 23:908-915. CrossRef Medline

Bychkov E, Ahmed MR, Dalby KN, Gurevich EV (2007) Dopamine depletion and subsequent treatment with L-DOPA, but not the long-lived dopamine agonist pergolide, enhances activity of the Akt pathway in the rat striatum. J Neurochem 102:699-711. CrossRef Medline

Canals M, Marcellino D, Fanelli F, Ciruela F, de Benedetti P, Goldberg SR, Neve K, Fuxe K, Agnati LF, Woods AS, Ferré S, Lluis C, Bouvier M, Franco R (2003) Adenosine A2A-dopamine D2 receptor-receptor heteromerization: qualitative and quantitative assessment by fluorescence and bioluminescence energy transfer. J Biol Chem 278:46741-46749. CrossRef Medline

Castello J, Ragnauth A, Friedman E, Rebholz H (2017) CK2: an emerging target for neurological and psychiatric disorders. Pharmaceuticals 10:e7. CrossRef Medline

Cenci MA, Tranberg A, Andersson M, Hilbertson A (1999) Changes in the regional and compartmental distribution of FosB- and JunB-like immunoreactivity induced in the dopamine-denervated rat striatum by acute or chronic L-dopa treatment. Neuroscience 94:515-527. CrossRef Medline

Cerovic M, Bagetta V, Pendolino V, Ghiglieri V, Fasano S, Morella I, Hardingham N, Heuer A, Papale A, Marchisella F, Giampà C, Calabresi P, Picconi B, Brambilla R (2015) Derangement of Ras-guanine nucleotidereleasing factor 1 (Ras-GRF1) and extracellular signal-regulated kinase (ERK) dependent striatal plasticity in L-DOPA-induced dyskinesia. Biol Psychiatry 77:106-115. CrossRef Medline

Chen JF, Xu K, Petzer JP, Staal R, Xu YH, Beilstein M, Sonsalla PK, Castagnoli K, Castagnoli N Jr, Schwarzschild MA (2001) Neuroprotection by caf- feine and $\mathrm{A}_{2 \mathrm{~A}}$ adenosine receptor inactivation in a model of Parkinson's disease. J Neurosci 21:RC143. Medline

Corvol JC, Muriel MP, Valjent E, Féger J, Hanoun N, Girault JA, Hirsch EC, Hervé D (2004) Persistent increase in olfactory type G-protein $\alpha$ subunit levels may underlie $D_{1}$ receptor functional hypersensitivity in Parkinson disease. J Neurosci 24:7007-7014. CrossRef Medline

Corvol JC, Valjent E, Pascoli V, Robin A, Stipanovich A, Luedtke RR, Belluscio L, Girault JA, Hervé D (2007) Quantitative changes in $\mathrm{G}_{\alpha}$ olf protein levels, but not D1 receptor, alter specifically acute responses to psychostimulants. Neuropsychopharmacology 32:1109-1121. CrossRef Medline

Dauer W, Przedborski S (2003) Parkinson's disease: mechanisms and models. Neuron 39:889-909. CrossRef Medline

Delfino MA, Stefano AV, Ferrario JE, Taravini IR, Murer MG, Gershanik OS (2004) Behavioral sensitization to different dopamine agonists in a parkinsonian rodent model of drug-induced dyskinesias. Behav Brain Res 152:297-306. CrossRef Medline

Díaz-Cabiale Z, Hurd Y, Guidolin D, Finnman UB, Zoli M, Agnati LF, Vanderhaeghen JJ, Fuxe K, Ferré S (2001) Adenosine A2A agonist CGS 21680 decreases the affinity of dopamine D2 receptors for dopamine in human striatum. Neuroreport 12:1831-1834. CrossRef Medline

Ding Y, Won L, Britt JP, Lim SA, McGehee DS, Kang UJ (2011) Enhanced striatal cholinergic neuronal activity mediates L-DOPA-induced dyskinesia in parkinsonian mice. Proc Natl Acad Sci U S A 108:840-845. CrossRef Medline

Fasano S, Bezard E, D’Antoni A, Francardo V, Indrigo M, Qin L, Doveró S, Cerovic M, Cenci MA, Brambilla R (2010) Inhibition of Ras-guanine nucleotide-releasing factor 1 (Ras-GRF1) signaling in the striatum reverts motor symptoms associated with L-dopa-induced dyskinesia. Proc Natl Acad Sci U S A 107:21824-21829. CrossRef Medline

Fisone G, Borgkvist A, Usiello A (2004) Caffeine as a psychomotor stimulant: mechanism of action. Cell Mol Life Sci 61:857-872. CrossRef Medline

Francardo V, Recchia A, Popovic N, Andersson D, Nissbrandt H, Cenci MA (2011) Impact of the lesion procedure on the profiles of motor impairment and molecular responsiveness to L-DOPA in the 6-hydroxydopamine mouse model of Parkinson's disease. Neurobiol Dis 42:327-340. CrossRef Medline

Fredholm BB, Lindström K (1999) Autoradiographic comparison of the potency of several structurally unrelated adenosine receptor antagonists at adenosine A1 and A(2A) receptors. Eur J Pharmacol 380:197-202. CrossRef Medline

Fuxe K, Tarakanov A, Romero Fernandez W, Ferraro L, Tanganelli S, Filip M, Agnati LF, Garriga P, Díaz-Cabiale Z, Borroto-Escuela DO (2014) Diversity and bias through receptor-receptor interactions in GPCR heteroreceptor complexes: focus on examples from dopamine D2 receptor heteromerization. Front Endocrinol (Lausanne) 5:71. CrossRef Medline

Gerfen CR, Engber TM, Mahan LC, Susel Z, Chase TN, Monsma FJ Jr, Sibley DR (1990) D1 and D2 dopamine receptor-regulated gene expression of striatonigral and striatopallidal neurons. Science 250:1429-1432. CrossRef Medline

Gerfen CR, Miyachi S, Paletzki R, Brown P (2002) D1 dopamine receptor supersensitivity in the dopamine-depleted striatum results from a switch in the regulation of ERK1/2/MAP kinase. J Neurosci 22:5042-5054. Medline

Gerfen CR, Paletzki R, Heintz N (2013) GENSAT BAC cre-recombinase driver lines to study the functional organization of cerebral cortical and basal ganglia circuits. Neuron 80:1368-1383. CrossRef Medline

Gong S, Doughty M, Harbaugh CR, Cummins A, Hatten ME, Heintz N, Gerfen CR (2007) Targeting Cre recombinase to specific neuron populations with bacterial artificial chromosome constructs. J Neurosci 27: 9817-9823. CrossRef Medline

Graybiel AM (2000) The basal ganglia. Curr Biol 10:R509-R511. CrossRef Medline

Grondin R, Bédard PJ, Hadj Tahar A, Grégoire L, Mori A, Kase H (1999) Antiparkinsonian effect of a new selective adenosine $\mathrm{A}_{2 \mathrm{~A}}$ receptor antagonist in MPTP-treated monkeys. Neurology 52:1673-1677. CrossRef Medline

Hauber W, Neuscheler P, Nagel J, Müller CE (2001) Catalepsy induced by a blockade of dopamine D1 or D2 receptors was reversed by a concomitant blockade of adenosine $\mathrm{A}_{2 \mathrm{~A}}$ receptors in the caudate-putamen of rats. Eur J Neurosci 14:1287-1293. CrossRef Medline

Hauser RA, Rascol O, Korczyn AD, Jon Stoessl A, Watts RL, Poewe W, De Deyn PP, Lang AE (2007) Ten-year follow-up of Parkinson's disease patients randomized to initial therapy with ropinirole or levodopa. Mov Disord 22:2409-2417. CrossRef Medline 
Heiman M, Heilbut A, Francardo V, Kulicke R, Fenster RJ, Kolaczyk ED, Mesirov JP, Surmeier DJ, Cenci MA, Greengard P (2014) Molecular adaptations of striatal spiny projection neurons during levodopa-induced dyskinesia. Proc Natl Acad Sci U S A 111:4578-4583. CrossRef Medline

Hervé D, Lévi-Strauss M, Marey-Semper I, Verney C, Tassin JP, Glowinski J, Girault JA (1993) $G_{\text {olf }}$ and $G_{s}$ in rat basal ganglia: possible involvement of $G_{\text {olf }}$ in the coupling of dopamine $D_{1}$ receptor with adenylyl cyclase. J Neurosci 13:2237-2248. Medline

Hirtz D, Thurman DJ, Gwinn-Hardy K, Mohamed M, Chaudhuri AR, Zalutsky R (2007) How common are the "common" neurologic disorders? Neurology 68:326-337. CrossRef Medline

Joghataie MT, Roghani M, Negahdar F, Hashemi L (2004) Protective effect of caffeine against neurodegeneration in a model of Parkinson's disease in rat: behavioral and histochemical evidence. Parkinsonism Relat Disord 10:465-468. CrossRef Medline

Kanda T, Jackson MJ, Smith LA, Pearce RK, Nakamura J, Kase H, Kuwana Y, Jenner P (1998) Adenosine $A_{2 A}$ antagonist: a novel antiparkinsonian agent that does not provoke dyskinesia in parkinsonian monkeys. Ann Neurol 43:507-513. CrossRef Medline

Lazarus M, Shen HY, Cherasse Y, Qu WM, Huang ZL, Bass CE, WinskySommerer R, Semba K, Fredholm BB, Boison D, Hayaishi O, Urade Y, Chen JF (2011) Arousal effect of caffeine depends on adenosine $A_{2 A}$ receptors in the shell of the nucleus accumbens. J Neurosci 31:1006710075. CrossRef Medline

Lebel M, Chagniel L, Bureau G, Cyr M (2010) Striatal inhibition of PKA prevents levodopa-induced behavioural and molecular changes in the hemiparkinsonian rat. Neurobiol Dis 38:59-67. CrossRef Medline

Lee G, Tanaka M, Park K, Lee SS, Kim YM, Junn E, Lee SH, Mouradian MM (2004) Casein kinase II-mediated phosphorylation regulates alphasynuclein/synphilin-1 interaction and inclusion body formation. J Biol Chem 279:6834-6839. CrossRef Medline

Le Moine C, Normand E, Bloch B (1991) Phenotypical characterization of the rat striatal neurons expressing the D1 dopamine receptor gene. Proc Natl Acad Sci U S A 88:4205-4209. CrossRef Medline

Lopez A, Muñoz A, Guerra MJ, Labandeira-Garcia JL (2001) Mechanisms of the effects of exogenous levodopa on the dopamine-denervated striatum. Neuroscience 103:639-651. CrossRef Medline

Lou DY, Dominguez I, Toselli P, Landesman-Bollag E, O’Brien C, Seldin DC (2008) The alpha catalytic subunit of protein kinase CK2 is required for mouse embryonic development. Mol Cell Biol 28:131-139. CrossRef Medline

Lundblad M, Andersson M, Winkler C, Kirik D, Wierup N, Cenci MA (2002) Pharmacological validation of behavioural measures of akinesia and dyskinesia in a rat model of Parkinson's disease. Eur J Neurosci 15:120-132. CrossRef Medline

Lundblad M, Usiello A, Carta M, Håkansson K, Fisone G, Cenci MA (2005) Pharmacological validation of a mouse model of 1-DOPA-induced dyskinesia. Exp Neurol 194:66-75. CrossRef Medline

Marcotte ER, Sullivan RM, Mishra RK (1994) Striatal G-proteins: effects of unilateral 6-hydroxydopamine lesions. Neurosci Lett 169:195-198. CrossRef Medline

Matsuya T, Takuma K, Sato K, Asai M, Murakami Y, Miyoshi S, Noda A, Nagai T, Mizoguchi H, Nishimura S, Yamada K (2007) Synergistic effects of adenosine A2A antagonist and L-DOPA on rotational behaviors in 6-hydroxydopamine-induced hemi-Parkinsonian mouse model. J Pharmacol Sci 103:329-332. CrossRef Medline

Miyamoto S, Duncan GE, Marx CE, Lieberman JA (2005) Treatments for schizophrenia: a critical review of pharmacology and mechanisms of action of antipsychotic drugs. Mol Psychiatry 10:79-104. CrossRef Medline

Olanow CW, Obeso JA (2000) Preventing levodopa-induced dyskinesias. Ann Neurol 47:S167-176; discussion S176-168. Medline

Pavón N, Martín AB, Mendialdua A, Moratalla R (2006) ERK phosphorylation and FosB expression are associated with L-DOPA-induced dyskinesia in hemiparkinsonian mice. Biol Psychiatry 59:64-74. CrossRef Medline
Penit-Soria J, Durand C, Besson MJ, Herve D (1997) Levels of stimulatory G protein are increased in the rat striatum after neonatal lesion of dopamine neurons. Neuroreport 8:829-833. CrossRef Medline

Pinna A, Fenu S, Morelli M (2001) Motor stimulant effects of the adenosine $\mathrm{A}_{2 \mathrm{~A}}$ receptor antagonist SCH 58261 do not develop tolerance after repeated treatments in 6-hydroxydopamine-lesioned rats. Synapse 39:233238. CrossRef Medline

Plotnikov A, Chuderland D, Karamansha Y, Livnah O, Seger R (2011) Nuclear extracellular signal-regulated kinase 1 and 2 translocation is mediated by casein kinase 2 and accelerated by autophosphorylation. Mol Cell Biol 31:3515-3530. CrossRef Medline

Postuma RB, Lang AE, Munhoz RP, Charland K, Pelletier A, Moscovich M, Filla L, Zanatta D, Rios Romenets S, Altman R, Chuang R, Shah B (2012) Caffeine for treatment of Parkinson disease: a randomized controlled trial. Neurology 79:651-658. CrossRef Medline

Prediger RD (2010) Effects of caffeine in Parkinson's disease: from neuroprotection to the management of motor and non-motor symptoms. JAD 20:S205-220. CrossRef Medline

Ramlackhansingh AF, Bose SK, Ahmed I, Turkheimer FE, Pavese N, Brooks DJ (2011) Adenosine 2A receptor availability in dyskinetic and nondyskinetic patients with Parkinson disease. Neurology 76:1811-1816. CrossRef Medline

Rangel-Barajas C, Silva I, Lopéz-Santiago LM, Aceves J, Erlij D, Florán B (2011) L-DOPA-induced dyskinesia in hemiparkinsonian rats is associated with up-regulation of adenylyl cyclase type V/VI and increased GABA release in the substantia nigra reticulata. Neurobiol Dis 41:51-61. CrossRef Medline

Rebholz H, Nishi A, Liebscher S, Nairn AC, Flajolet M, Greengard P (2009) CK2 negatively regulates $\mathrm{G} \alpha$ s signaling. Proc Natl Acad Sci U S A 106: 14096-14101. CrossRef Medline

Rebholz H, Zhou M, Nairn AC, Greengard P, Flajolet M (2013) Selective knockout of the casein kinase 2 in D1 medium spiny neurons controls dopaminergic function. Biol Psychiatry 74:113-121. CrossRef Medline

Rosin DL, Hettinger BD, Lee A, Linden J (2003) Anatomy of adenosine $A_{2 A}$ receptors in brain: morphological substrates for integration of striatal function. Neurology 61:S12-18. CrossRef Medline

Ryu MY, Kim DW, Arima K, Mouradian MM, Kim SU, Lee G (2008) Localization of CKII $\beta$ subunits in Lewy bodies of Parkinson's disease. J Neurol Sci 266:9-12. CrossRef Medline

Santini E, Valjent E, Usiello A, Carta M, Borgkvist A, Girault JA, Hervé D, Greengard P, Fisone G (2007) Critical involvement of cAMP/DARPP-32 and extracellular signal-regulated protein kinase signaling in L-DOPAinduced dyskinesia. J Neurosci 27:6995-7005. CrossRef Medline

Santini E, Alcacer C, Cacciatore S, Heiman M, Hervé D, Greengard P, Girault JA, Valjent E, Fisone G (2009) L-DOPA activates ERK signaling and phosphorylates histone $\mathrm{H} 3$ in the striatonigral medium spiny neurons of hemiparkinsonian mice. J Neurochem 108:621-633. CrossRef Medline

Undie AS, Friedman E (1988) Differences in the cataleptogenic actions of SCH23390 and selected classical neuroleptics. Psychopharmacology 96: 311-316. CrossRef Medline

Westin JE, Vercammen L, Strome EM, Konradi C, Cenci MA (2007) Spatiotemporal pattern of striatal ERK1/2 phosphorylation in a rat model of L-DOPA-induced dyskinesia and the role of dopamine D1 receptors. Biol Psychiatry 62:800-810. CrossRef Medline

Won L, Ding Y, Singh P, Kang UJ (2014) Striatal cholinergic cell ablation attenuates L-DOPA induced dyskinesia in Parkinsonian mice. J Neurosci 34:3090-3094. CrossRef Medline

Xiao D, Cassin JJ, Healy B, Burdett TC, Chen JF, Fredholm BB, Schwarzschild MA (2011) Deletion of adenosine $A_{1}$ or $A_{2 A}$ receptors reduces L-3,4dihydroxyphenylalanine-induced dyskinesia in a model of Parkinson's disease. Brain Res 1367:310-318. CrossRef Medline

Zheng Y, McFarland BC, Drygin D, Yu H, Bellis SL, Kim H, Bredel M, Benveniste EN (2013) Targeting protein kinase CK2 suppresses prosurvival signaling pathways and growth of glioblastoma. Clin Cancer Res 19:64846494. CrossRef Medline 